\title{
Analytical Solution for Circular Tunnel under Obliquely Incident $P$ Waves considering Different Contact Conditions
}

\author{
Yawei Duan $\mathbb{D}^{1},{ }^{1}$ Mi Zhao, ${ }^{1}$ Jingqi Huang $\mathbb{D},{ }^{2}$ Huifang Li, ${ }^{1}$ and Xiuli Du ${ }^{1}$ \\ ${ }^{1}$ Key Laboratory of Urban Security and Disaster Engineering of Ministry of Education, Beijing University of Technology, \\ Beijing 100124, China \\ ${ }^{2}$ Beijing Key Laboratory of Urban Underground Space Engineering, School of Civil and Resource Engineering, \\ University of Science and Technology Beijing, Beijing 100083, China \\ Correspondence should be addressed to Jingqi Huang; huangjingqi11@163.com
}

Received 18 June 2021; Revised 30 September 2021; Accepted 23 November 2021; Published 22 December 2021

Academic Editor: Mahmoud Bayat

Copyright (C) 2021 Yawei Duan et al. This is an open access article distributed under the Creative Commons Attribution License, which permits unrestricted use, distribution, and reproduction in any medium, provided the original work is properly cited.

\begin{abstract}
An analytical solution for the seismic-induced thrust and moment of the circular tunnel in half-space under obliquely incident $\mathrm{P}$ waves is developed in this study, which is the superposition of the solution for deep tunnels under incident and reflected $\mathrm{P}$ waves and the reflected SV waves. To consider tangential contact stiffness at the ground-tunnel interface, a spring-type stiffness coefficient is introduced into the force-displacement relationship. Moreover, the tunnel lining is treated as the thick-wall cylinder, providing more precise forecasts than beam or shell models used in previous analytical solution, especially for tunnels with thick lining. The reliability of the proposed analytical solution is assessed by comparing with the dynamic numerical results. Based on the proposed analytical solution, parametrical studies are conducted to investigate the effect of some critical factors on the tunnel's seismic response, including the incident angles, the tangential contact stiffness at the ground-tunnel interface, and the relative stiffness between the ground and the tunnel. The results demonstrate that the proposed analytical solution performs well and can be adopted to predict the internal forces of circular tunnels under obliquely incident $\mathrm{P}$ waves in seismic design.
\end{abstract}

\section{Introduction}

As the essential part of infrastructures, tunnel structures play an important role in public transportation facilities, sanitation frameworks, irrigation utilities, and so on. Besides thousands of land tunnels, many undersea tunnels are constructed or under the plan for construction with the rapid development of coastal transportation in recent years. However, seismic damage cases in recent years indicate that tunnel structures are vulnerable to earthquake loading [1-4]. Sometimes, a low level of tunnel damage may affect structural serviceability and bring about substantial life and property lost, especially for undersea tunnels. Therefore, the tunnel linings should be carefully designed using an effective design method to withstand the additional loads arising from earthquakes.

In the last several decades, plenty of seismic analysis and design methods have been developed for tunnels and other underground structures, which can be divided into analytical solution, quasi-static analysis method, and dynamic time history analysis method. Compared with the quasistatic analysis method and dynamic time history analysis method, the analytical solution can quickly and easily estimate the force and displacement of the tunnel under seismic loadings, which can identify the most relevant variables of the problem. Therefore, analytical solution has been widely used in the preliminary seismic design of tunnels. Many researchers have been conducted to develop analytical solution of circular tunnels for seismic analysis. Wang [5] proposed the analytical solution for thrust, moment, and deformation of the circular tunnel under vertically propagating shear waves. Penzien and $\mathrm{Wu}[6]$ put forward a simple formula for calculating the deformation and corresponding stress of bored tunnels resulting from earthquake loading. Then, Penzien [7] supplemented the previously published by Penzien and $\mathrm{Wu}[6]$ and proposed a 
method to calculate the deformation of rectangular and circular tunnel lining under seismic action. The above analytical solution assumes full-slip condition or no-slip condition between the ground and the tunnel lining. However, the contact state at the ground-tunnel interface is between full-slip and no-slip. In this regard, Park et al. [8] established a new analytical solution by using a spring-type flexibility coefficient $D$ to consider the slippage effect of the ground-tunnel interface. Fang et al. [9] introduced the elastic-slip interface model to simulate the ground-tunnel interface properties and analyzed the dynamic response of twin tunnels subjected to blast waves. Then, Li et al.[10] used the same elastic-slip interface model and analyzed the influence of the elastic-slip interface in saturated poroelastic soil on the dynamic response of the underwater tunnel subjected to plane waves. Another important assumption adopted by most analytical solution is dry soil conditions. Bobet $[11,12]$ considered the influence of pore water pressure and presented an analytical solution for the circular tunnel subjected to seismic loads for drained and undrained loading conditions. All the above analytical solution are derived by assuming the tunnel lining as a beam or shell model, and there is a certain error for thick lining tunnels $[13,14]$. Therefore, it is necessary to use a thick-wall cylinder to simulate the tunnel lining. Another important assumption is that the tunnel is assumed to be located in the fullspace, and the seismic wave is considered as vertical incidence. In fact, the buried depth of the tunnel is usually limited, and the seismic incident direction has a significant impact on the underground structure in half-space [15-18]. Huang et al. [19] derived an analytical solution of the circular tunnel under obliquely incident SV waves based on a thickwall cylinder model, considering the no-slip interface condition. Many studies show that the obliquely incident $\mathrm{P}$ waves has great influence on the seismic response of structures [20-24]. However, the analytical solution of the circular tunnel under obliquely incident $\mathrm{P}$ waves based on thick-wall cylinder model considering different contact conditions of the ground-tunnel interface is limited.

In this paper, a new analytical solution for the internal force of the circular tunnel in half-space under obliquely incident $\mathrm{P}$ waves is developed by using a thick-walled cylinder to simulate the tunnel lining and introducing a springtype stiffness coefficient $k$ to consider the different tangential contact stiffness at the ground-tunnel interface. Then, the accuracy and applicability of the new analytical solution are verified by comparison with the dynamic time history analysis method. Finally, the effects of $\mathrm{P}$ waves' incident angle, stiffness coefficient, and flexibility ratio are discussed.

\section{Formulation of the Problem}

Most of works $[5,7,8,12]$ assumed the earthquake motions as the plane body waves propagating along a vertical direction. In fact, the earthquake waves always have an arbitrary propagating direction [21]. Consider a circular tunnel located below the ground and subjected to obliquely incident $\mathrm{P}$ waves, as shown in Figure 1. The outer and inner radii are $R$ and $r$, respectively, with the center $O$ and the

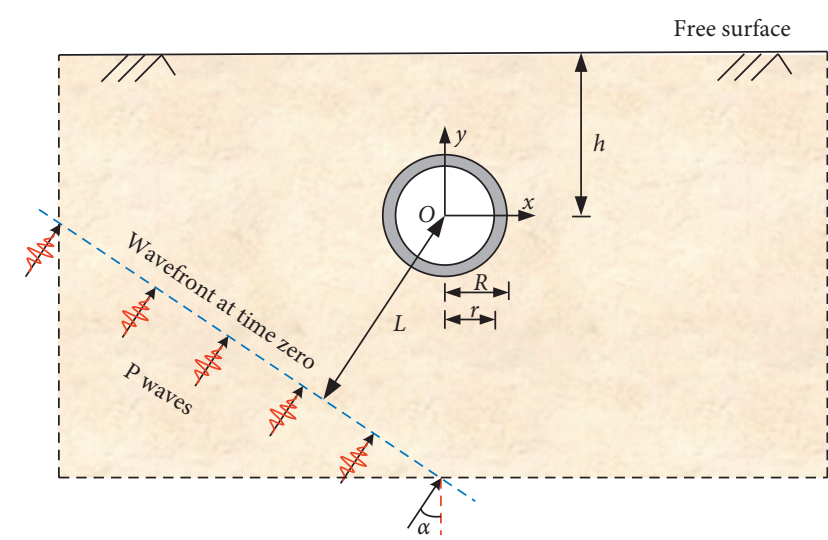

FIgURE 1: Ground-tunnel interaction system in half-space under obliquely incident $\mathrm{P}$ waves.

depth $h$ under the half-space surface. The seismic excitation is a $\mathrm{P}$ wave with an incident angle of $\alpha$ in the $x-y$ plane, and the distance between the wavefront at the zero time of the $\mathrm{P}$ waves and the center of the tunnel $O$ is $L$. For the plane strain problem shown in Figure 1, the tunnel lining and its surrounding ground are assumed to be homogeneous isotropic linear elastic medium. The soft soil has nonlinear behavior under earthquake; linear elastic assumption may limit the practical applicability of the results obtained. However, the analytical solution develops a simple formulation for the preliminary seismic design of the tunnel, which can be used for further analysis. While reducing the calculation effort, some parameters that can reflect the real mechanical behavior of soil are discarded. At the same time, the analytical solution contains the most critical variables in the problem. Moreover, this study aims to the quasi-static analytical solution on the seismic-induced internal forces of the tunnel lining. Therefore, the geostatic stress is not considered. As we all know, the seismic response of underground structure is dominated by the surrounding ground response but not the inertial properties of the structure itself $[19,25]$. Therefore, the dynamic inertial effect is ignored in the following derivation.

\section{New Analytical Solution}

3.1. Wave Motions in Half-Space Ground and Pseudostatic Analysis Model. The free filed wave motions in the halfspace ground under obliquely incident $\mathrm{P}$ waves are shown in Figure 2. The incident $P$ waves reach the ground surface with an oblique angle of $\alpha$. According to the wave motion theories [26], reflected $P$ waves and SV waves are generated at the free surface, with the reflected angles of $\alpha$ and $\beta$, respectively. As the tunnel being constructed in the ground, the tunnel will be excited by three waves, i.e., incident $\mathrm{P}$ waves, reflected $\mathrm{P}$ waves, and reflected SV waves. Therefore, the seismic response of the tunnel is superposition of the response of the tunnel under these three waves. In order to calculate the tunnel's response conveniently, local coordinate systems $\left(\eta_{1}\right.$, $\left.\xi_{1}\right),\left(\eta_{2}, \xi_{2}\right)$, and $\left(\eta_{3}, \xi_{3}\right)$ are adopted for the three waves, respectively. In local coordinate systems, the velocity-time histories of the three waves are as follows: 


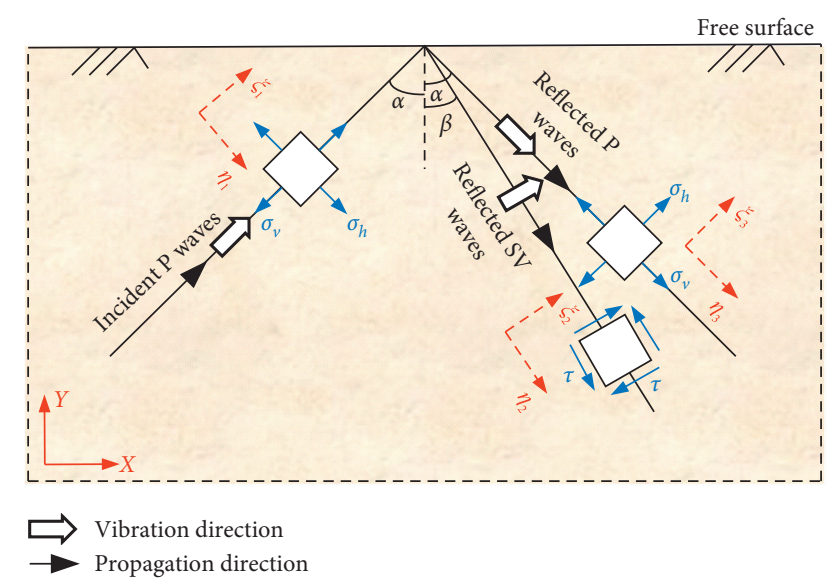

Figure 2: Wave motions in half-space under obliquely incident $\mathrm{P}$ waves.

$$
\left\{\begin{array}{l}
v_{1}(t)=v_{0}\left(t-\Delta t_{1}\right), \\
v_{2}(t)=A_{1} v_{0}\left(t-\Delta t_{2}\right), \\
v_{3}(t)=A_{2} v_{0}\left(t-\Delta t_{3}\right),
\end{array}\right.
$$

where $A_{1}$ and $A_{2}$ are the amplitudes of the reflected $\mathrm{P}$ waves and the reflected SV wave, $\Delta t_{1}, \Delta t_{2}$, and $\Delta t_{3}$ are the wave propagation times of the incident $\mathrm{P}$ waves, the reflected $\mathrm{P}$ waves, and the reflected SV waves from the zero-time wavefront to the center location of the tunnel, respectively, and $t$ stands for time. These parameters can be expressed as [27]

$$
\begin{aligned}
& \left\{\begin{array}{l}
A_{1}=\frac{c_{s}^{2} \sin 2 \alpha \sin 2 \beta-c_{p}^{2} \cos ^{2} 2 \beta}{c_{s}^{2} \sin 2 \alpha \sin 2 \beta+c_{p}^{2} \cos ^{2} 2 \beta} \\
A_{2}=-\frac{2 c_{p} c_{s} \sin 2 \alpha \cos 2 \beta}{c_{s}^{2} \sin 2 \alpha \sin 2 \beta+c_{p}^{2} \cos ^{2} 2 \beta} \\
\beta=\arcsin \left(\frac{c_{s} \sin \alpha}{c_{p}}\right) \\
\Delta t_{1}=\frac{L}{c_{p}}, \\
\Delta t_{2}=\frac{L+2 h \cos \alpha}{c_{p}}, \\
\Delta t_{3}=\left(\frac{L+h \cos \alpha-h \sin \alpha \tan \beta}{c_{p}}\right)+\left(\frac{h}{c_{s} \cos \beta}\right)
\end{array}\right.
\end{aligned}
$$

Where $c_{s}$ and $c_{p}$ are the shear wave velocity and compression wave velocity in the ground.

As the wave length of peak velocities is at least 8 times larger than the width of the opening, the free-field stress gradient across the opening is relatively small and the seismic loading can be considered as a pseudo-static load. In most underground openings the quasi-static conditions are usually satisfied $[11,12]$. Therefore, the pseudo-static approach is employed to analysis the tunnel response under the three waves. The pseudo-static approach is an accepted method of analysis in current seismic design practice, which has been widely used in earlier studies for analytical solution $[6-8,11,19,28]$. In the pseudo-static approach, the incident seismic wave is simulated by applying a static far-field stress or strain at the model boundaries to represent the seismic effects. Figure 3 offers the pseudo-static analysis model of the ground-tunnel system for the incident and reflected $\mathrm{P}$ waves and reflected SV waves, respectively.

The compressive stress $\sigma_{\nu 1}$ and $\sigma_{h 1}$ caused by incident $\mathrm{P}$ waves, the compressive stress $\sigma_{\nu 2}$ and $\sigma_{h 2}$ caused by reflected $\mathrm{P}$ wave, and the shear stress $\tau$ caused by reflected SV wave can be expressed as

$$
\begin{aligned}
& \left\{\begin{array}{l}
\sigma_{v 1}(t)=\frac{E_{g}\left(1-v_{g}\right)}{\left(1+v_{g}\right)\left(1-2 v_{g}\right) c_{p}} v_{0}\left(t-\Delta t_{1}\right), \\
\sigma_{h 1}(t)=\frac{E_{g} v_{g}}{\left(1+v_{g}\right)\left(1-2 v_{g}\right) c_{p}} v_{0}\left(t-\Delta t_{1}\right),
\end{array}\right. \\
& \left\{\begin{array}{l}
\sigma_{v 2}(t)=\frac{E_{g}\left(1-v_{g}\right)}{\left(1+v_{g}\right)\left(1-2 v_{g}\right) c_{p}} A_{1} v_{0}\left(t-\Delta t_{2}\right), \\
\sigma_{h 2}(t)=\frac{E_{g} v_{g}}{\left(1+v_{g}\right)\left(1-2 v_{g}\right) c_{p}} A_{1} v_{0}\left(t-\Delta t_{2}\right),
\end{array}\right. \\
& \tau(t)=-\frac{E_{g}}{2\left(1+v_{g}\right) c_{s}} A_{2} v_{0}\left(t-\Delta t_{3}\right),
\end{aligned}
$$

where $t$ stands for time and $E_{g}$ and $v_{g}$ represent Young's modulus and Poisson's ratio of the ground, respectively.

In the following section, the analytical solution of the tunnel's internal force under the incident $\mathrm{P}$ waves, the reflected $\mathrm{P}$ waves, and the reflected SV waves will be, respectively, derived. Then, the three solution are linearly superimposed to obtain the final solution of the tunnel.

3.2. Internal Force of Tunnel under Reflected SV Waves. This section gives the analytical solution of a circular tunnel under reflected SV waves, and the pseudo-static groundtunnel interaction system is shown in Figure 3(b). The shear stress can be obtained from Equation (5). Different from previous researchers such as Hoeg [29], Penzien [7], Park et al. [8], and Bobet $[11,12]$, who regarded the tunnel lining as a beam or a shell, this paper regards the tunnel lining as a thick-wall cylinder, which reduces the errors brought by the thick lining to the analytical solution. Moreover, we introduce a spring-type stiffness coefficient $k$ to consider the tangential contact stiffness at the ground-tunnel interface.

The model of the ground-tunnel system in local coordinate system $(\eta, \xi)$, as shown in Figure 3(b), is transformed to the polar coordinates $(\rho, \varphi)$, as shown in Figure 4(a). 
Using coordinate transformation, the far-field shear stress can be expressed as

$$
\left\{\begin{array}{l}
\left.\sigma_{\rho}\right|_{\rho=\infty}=\tau \sin 2 \varphi \\
\left.\tau_{\rho \varphi}\right|_{\rho=\infty}=\tau \cos 2 \varphi .
\end{array}\right.
$$

For the convenience in analysis, as shown in Figure 4(a), the ground-tunnel system was decomposed into two cases: (1) a circular cylindrical cavity subjected to far-field shear stress and contact stress at the ground-tunnel interface (Figure 4(b)); (2) thick-walled cylinder subjected to contact stress at the groundtunnel interface (Figure $4(\mathrm{c})$ ). The ground-tunnel interface's normal and tangential contact stresses can be expressed as $p \sin 2 \varphi$ and $q \cos 2 \varphi[6,28]$. In the following formula, subscripts $g$ and $l$ represent the ground and the tunnel, respectively, and subscripts $\rho$ and $\varphi$ represent the radial and circumferential directions.

To consider the relationship between displacement and interaction forces at the ground-tunnel interface, following the work of Park et al. [8], a spring-type stiffness coefficient $k$ is introduced. $k \longrightarrow 0$ and $k \longrightarrow \infty$ are two extreme states, which represent the full-slip interface condition and the no-slip interface condition, respectively. The displacement and stress at the interface $(\rho=R)$ should be satisfied, namely,

$$
\begin{aligned}
& \left\{\begin{array}{l}
\left.u_{\rho(g)}\right|_{\rho=R}=\left.u_{\rho(l)}\right|_{\rho=R}, \\
\left.u_{\varphi(g)}\right|_{\rho=R}=\left.u_{\varphi(l)}\right|_{\rho=R}+\frac{q \cos 2 \varphi}{k},
\end{array}\right. \\
& \left\{\begin{array}{l}
\left.\tau_{\rho \varphi(g)}\right|_{\rho=R}=\left.\tau_{\rho \varphi(l)}\right|_{\rho=R}, \\
\left.\sigma_{\rho(g)}\right|_{\rho=R}=\left.\sigma_{\rho(l)}\right|_{\rho=R} .
\end{array}\right.
\end{aligned}
$$

The displacement and stress components of the cylinder in polar coordinates are obtained from the theory of elasticity [30]:

$$
\begin{aligned}
& \left\{\begin{array}{l}
u_{\rho}=-m\left(2 B \rho-\frac{4 C}{\rho}-\frac{2 D}{\rho^{3}}\right) \sin 2 \varphi+n\left(4 A \rho^{3}+2 B \rho-\frac{2 D}{\rho^{3}}\right) \sin 2 \varphi+I \sin \varphi+K \cos \varphi, \\
u_{\varphi}=-\frac{m}{2}\left(12 A \rho^{3}+4 B \rho-\frac{4 C}{\rho}+\frac{4 D}{\rho^{3}}\right) \cos 2 \varphi+\frac{n}{2}\left(4 A \rho^{3}+4 B \rho+\frac{4 C}{\rho}+\frac{4 D}{\rho^{3}}\right) \cos 2 \varphi+I \cos \varphi-K \sin \varphi,
\end{array}\right. \\
& \left\{\begin{array}{l}
\sigma_{\rho}=-\left(2 B+\frac{4 C}{\rho^{2}}+\frac{6 D}{\rho^{4}}\right) \sin 2 \varphi \\
\sigma_{\varphi}=\left(12 A \rho^{2}+2 B+\frac{6 D}{\rho^{4}}\right) \sin 2 \varphi \\
\tau_{\rho \varphi}=-\left(6 A \rho^{2}+2 B-\frac{2 C}{\rho^{2}}-\frac{6 D}{\rho^{4}}\right) \cos 2 \varphi
\end{array}\right.
\end{aligned}
$$

where $A, B, C, D, I$, and $K$ are undetermined constants and $I$ and $K$ represent the rigid body displacement components. $m$ and $n$ are expressed by Young's modulus $E$ and Poisson's ratio $v$, which are $\left(1-v^{2}\right) / E$ and $\left(v+v^{2}\right) / E$, respectively.

Substituting equation (10) into (6), we can obtain

$$
\left\{\begin{array}{l}
\left.\tau_{\rho \varphi(g)}\right|_{\rho=\infty}=-\left(6 A_{g} \rho^{2}+2 B_{g}-\frac{2 C_{g}}{\rho^{2}}-\frac{6 D_{g}}{\rho^{4}}\right) \cos 2 \varphi=\tau \cos 2 \varphi \\
\left.\sigma_{\rho(g)}\right|_{\rho=\infty}=-\left(2 B_{g}+\frac{4 C_{g}}{\rho^{2}}+\frac{6 D_{g}}{\rho^{4}}\right) \sin 2 \varphi=\tau \sin 2 \varphi .
\end{array}\right.
$$




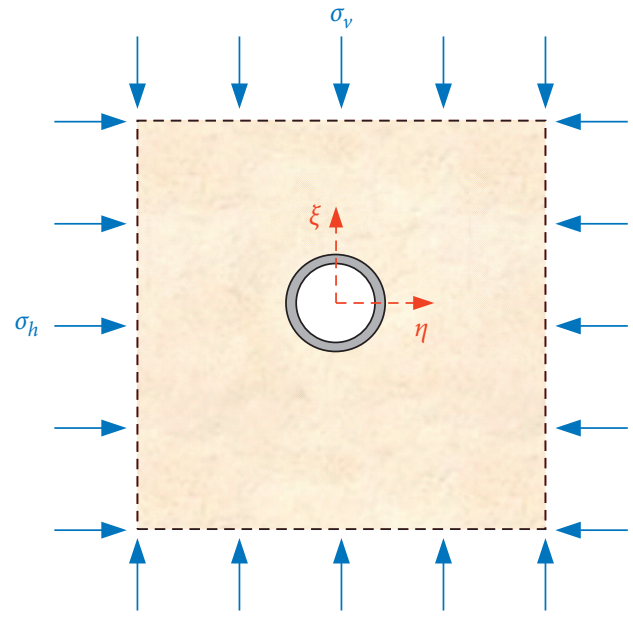

(a)

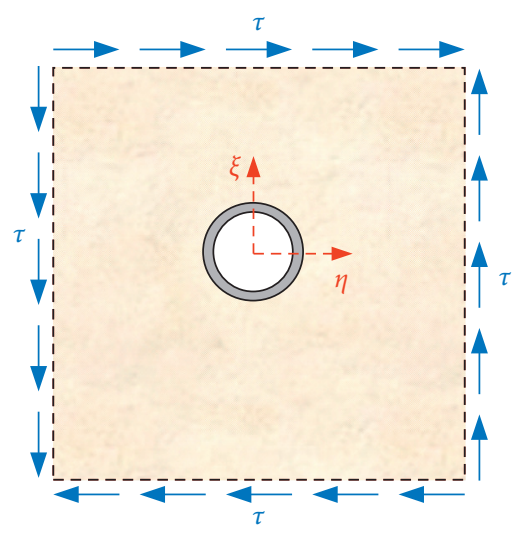

(b)

FIGURE 3: The pseudo-static analysis model of the ground-tunnel system: (a) for the incident $\mathrm{P}$ waves and reflected $\mathrm{P}$ waves and (b) for the reflected SV waves.

When $\rho \longrightarrow \infty, 1 / \rho^{2}$ and $1 / \rho^{4}$ tend to 0 . Therefore, it can be concluded that

$$
\left\{\begin{array}{l}
A_{g}=0, \\
B_{g}=-\frac{\tau}{2} .
\end{array}\right.
$$

Because the inner surface of the tunnel is free, the following boundary conditions are satisfied:

$$
\left\{\begin{array}{l}
\left.\tau_{\rho \varphi(l)}\right|_{\rho=r}=-\left(6 A_{l} r_{2}+2 B_{l}-\frac{2 C_{l}}{r^{2}}-\frac{6 D_{l}}{r^{4}}\right) \cos 2 \varphi=0, \\
\left.\sigma_{\rho(l)}\right|_{\rho=r}=-\left(2 B_{l}+\frac{4 C_{l}}{r^{2}}+\frac{6 D_{l}}{r^{4}}\right) \sin 2 \varphi=0 .
\end{array}\right.
$$

Substitute equation (10) into (8) to obtain

$$
\left\{\begin{array}{l}
6 A_{l} R^{2}+2 B_{l}-\left(\frac{2 C_{l}}{R^{2}}-\frac{6 D_{l}}{R^{4}}\right)-6 A_{g} R^{2}-2 B_{g}+\left(\frac{2 C_{g}}{R^{2}}+\frac{6 D_{g}}{R^{4}}\right)=0, \\
2 B_{l}+\left(\frac{4 C_{l}}{R^{2}}+\frac{6 D_{l}}{R^{4}}\right)-2 B_{g}-\left(\frac{4 C_{g}}{R^{2}}-\frac{6 D_{g}}{R^{4}}\right)=0 .
\end{array}\right.
$$

Substitute equation (9) into Equation (7), and it becomes

$$
\left\{\begin{array}{l}
-m_{g}\left(2 B_{g} R-\frac{4 C_{g}}{R}-\frac{2 D_{g}}{R^{3}}\right) \sin 2 \varphi+n_{g}\left(4 A_{g} R^{3}+2 B_{g} R-\frac{2 D_{g}}{R^{3}}\right) \sin 2 \varphi+I_{g} \sin \varphi+K_{g} \cos \varphi=-m_{l}\left(2 B_{l} R-\frac{4 C_{l}}{R}-\frac{2 D_{l}}{R^{3}}\right) \sin 2 \varphi \\
+n_{l}\left(4 A_{l} R^{3}+2 B_{l} R-\frac{2 D_{l}}{R^{3}}\right) \sin 2 \varphi+I_{l} \sin \varphi+K_{l} \cos \varphi-\frac{m_{g}}{2}\left(12 A_{g} R^{3}+4 B_{g} R-\frac{4 C_{g}}{R}+\frac{4 D_{g}}{R^{3}}\right) \cos 2 \varphi \\
+\frac{n_{g}}{2}\left(4 A_{g} R^{3}+4 B_{g} R+\frac{4 C_{g}}{R}+\frac{4 D_{g}}{R^{3}}\right) \cos 2 \varphi+I_{g} \cos \varphi-K_{g} \sin \varphi+\frac{q \cos 2 \varphi}{k} \\
=-\frac{m_{l}}{2}\left(12 A_{l} R^{3}+4 B_{l} R-\frac{4 C_{l}}{R}+\frac{4 D_{l}}{R^{3}}\right) \cos 2 \varphi+\frac{n_{l}}{2}\left(4 A_{l} R^{3}+4 B_{l} R+\frac{4 C_{l}}{R}+\frac{4 D_{l}}{R^{3}}\right) \cos 2 \varphi+I_{l} \cos \varphi-K_{l} \sin \varphi .
\end{array}\right.
$$




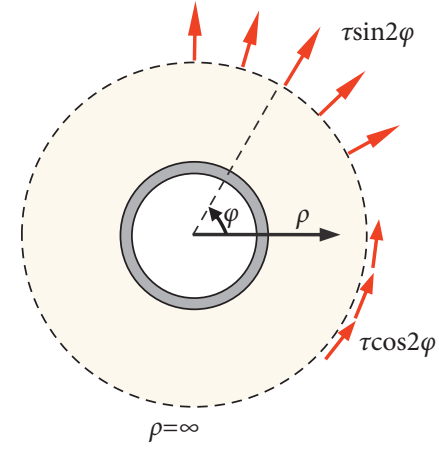

(a)

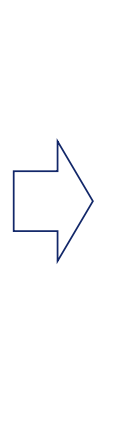

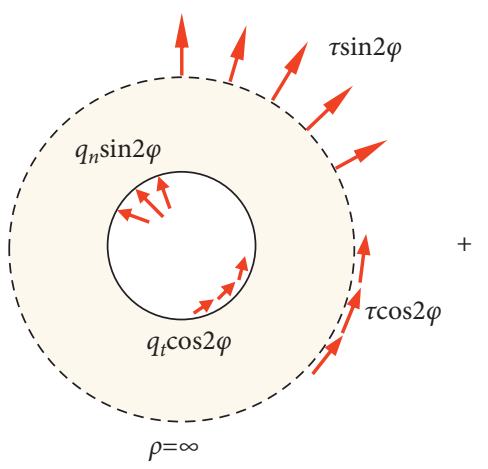

(b)

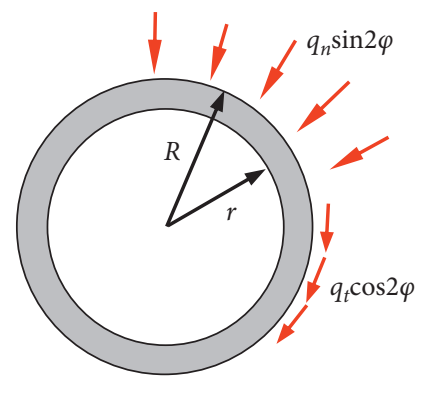

(c)

Figure 4: Decomposition of the ground-tunnel system under S waves: (a) ground-tunnel system in polar coordinates; (b) ground system; (c) tunnel system.

Equation (15) should be established when $\varphi$ takes any value. Substituting $\varphi=0$ and $\varphi=3 \pi / 4$ into Equation (15), one obtains

$$
\left\{\begin{array}{l}
I_{g}=I_{l} \\
K_{g}=K_{l}
\end{array}\right.
$$

$$
q \cos 2 \varphi=-\tau_{\rho \varphi}(l)=\left(6 A_{l} R^{2}+2 B_{l}-\frac{2 C_{l}}{R^{2}}-\frac{6 D_{l}}{R^{4}}\right) \cos 2 \varphi .
$$

Substitute equations (16) and (17) into (15) to simplify

The tangential contact stress can be expressed as

$$
\left\{\begin{array}{l}
4 n_{l} R^{3} A_{l}-2\left(m_{l}-n_{l}\right) R B_{l}+\frac{4 m_{l}}{R} C_{l}+2 \frac{m_{l}-n_{l}}{R^{3}} D_{l}-4 n_{l} R^{3} A_{g}+2\left(m_{g}-n_{g}\right) R B_{g}-\frac{4 m_{g}}{R} C_{g}-2 \frac{m_{g}-n_{g}}{R^{3}} D_{g}=0 \\
{\left[-\left(6 m_{l}-2 n_{l}\right) R^{3}+\frac{6 R^{2}}{k}\right] A_{l}+\left[-2\left(m_{l}-n_{l}\right) R+\frac{2}{k}\right] B_{l}+\left[2 \frac{m_{l}+n_{l}}{R}-\frac{2}{k R^{2}}\right] C_{l}} \\
+\left[-2 \frac{m_{l}-n_{l}}{R^{3}}-\frac{6}{k R^{4}}\right] D_{l}+\left(6 m_{g}-2 n_{g}\right) R^{3} A_{g}+2\left(m_{g}-n_{g}\right) R B_{g}-2 \frac{m_{g}+n_{g}}{R} C_{g}+2 \frac{m_{g}-n_{g}}{R^{3}} D_{g}=0 .
\end{array}\right.
$$

Solving equations (12), (13), (14), and (18) simultaneously, the constants $A_{l}, B_{l}, C_{l}$, and $D_{l}$ can be solved as

$$
\left\{\begin{array}{l}
A_{1}=-\frac{\eta^{4}\left(q_{n}-q_{t}\right)+3 \eta^{2}\left(q_{n}+q_{t}\right)}{6\left(\eta^{2}-1\right)^{3} r_{0}^{2}} \tau, \\
B_{1}=\frac{\left(\eta^{6}+\eta^{4}+2 \eta^{2}\right) q_{n}+2 \eta^{2} q_{t}}{2\left(\eta^{2}-1\right)^{3}} \tau, \\
C_{1}=-\frac{r_{1}^{2}\left[2 \eta^{4} q_{n}+\left(\eta^{2}+1\right)\left(q_{n}+q_{t}\right)\right]}{2\left(\eta^{2}-1\right)^{3}} \tau, \\
D_{1}=\frac{r_{0}^{4}\left(3 \eta^{6} q_{n}+\eta^{4} q_{n}+2 \eta^{4} q_{t}\right)}{6\left(\eta^{2}-1\right)^{3}} \tau,
\end{array}\right.
$$


where $q_{n}, q_{t}$, and $\eta$ are expressed as

$$
\left\{\begin{array}{l}
q_{n}=\frac{-4 m_{g}\left(\left(m_{g}-n_{g} / 3\right) R+\delta_{12}+\delta_{22}+(1 / k) R\right)}{\left(\left(4 m_{g}+2 n_{g} / 3\right) R-\delta_{12}\right)\left(\left(m_{g}-n_{g} / 3\right) R+\delta_{12}+\delta_{22}+(1 / k)\right)+\left(\left(m_{g}-n_{g} / 3\right) R-\delta_{11}+\delta_{12}\right)\left(\left(5 m_{g}+n_{g} / 3\right) R+\delta_{22}+(1 / k)\right)} \\
q_{t}=\frac{-4 m_{g}\left(\left(m_{g}-n_{g} / 3\right) R-\delta_{11}+\delta_{12}\right) R}{\left(\left(4 m_{g}+2 n_{g} / 3\right) R-\delta_{12}\right)\left(\left(m_{g}-n_{g} / 3\right) R+\delta_{12}+\delta_{22}+(1 / k)\right)+\left(\left(m_{g}-n_{g} / 3\right) R-\delta_{11}+\delta_{12}\right)\left(\left(5 m_{g}+n_{g} / 3\right) R+\delta_{22}+(1 / k)\right)} \\
\delta_{11}=2 r \frac{\left(n_{l}-3 m_{l}\right)\left(\eta^{7}+3 \eta^{3}\right)-\left(n_{l}+5 m_{l}\right)\left(3 \eta^{5}+\eta\right)}{6\left(\eta^{2}-1\right)^{3}} \\
\delta_{12}=4 r \frac{n_{l} \eta^{7}-3 n_{l} \eta^{5}+3\left(n_{l}-2 m_{l}\right) \eta^{3}-\left(n_{l}+2 m_{l}\right) \eta}{6\left(\eta^{2}-1\right)^{3}} \\
\delta_{22}=2 r \frac{\left(3 m_{l}-n_{l}\right)\left(\eta^{7}-3 \eta^{5}+3 \eta^{3}\right)+\left(n_{l}+5 m_{l}\right) \eta}{6\left(\eta^{2}-1\right)^{3}} \\
\eta=\frac{R}{r_{0}} .
\end{array}\right.
$$

The thrust and the moment of the tunnel can be obtained by integration:

$$
\left\{\begin{array}{l}
T_{s v}=\int_{r}^{R} \sigma_{\varphi} \mathrm{d} \rho \\
M_{s v}=\int_{r}^{R} \sigma_{\varphi}\left(\rho-\frac{R+r}{2}\right) \mathrm{d} \rho .
\end{array}\right.
$$

Substitute equation (19) into (10) and then into equation (21). Finally, the analytical solution for the thrust $T_{s v}$ and the moment $M_{s v}$ of the circular tunnel under far-field shear stress in the local coordinate system $(\eta, \xi)$ is obtained:

$$
\left\{\begin{array}{l}
T_{s v}=\frac{R}{3}\left(q_{n}+2 q_{t}\right) \tau \sin 2 \varphi \\
M_{s v}=\frac{3 R^{2} q_{t}-\left(R^{2}+R r_{0}\right)\left(q_{n}+2 q_{t}\right)}{6} \tau \sin 2 \varphi
\end{array}\right.
$$

Since the propagation angle of the reflected SV waves in the $(X, Y)$ coordinate system is $\pi-\beta$, the tunnel thrust $T_{s v r}$ and moment $M_{s v r}$ under the shearing stress $\tau$ caused by the reflected SV waves can be obtained from Equation (22) by simply rotating the angle $\pi-\beta$ :

$$
\left\{\begin{array}{l}
T_{s v r}=\frac{R}{3}\left(q_{n}+2 q_{t}\right) \tau \sin 2(\varphi+\pi-\beta), \\
M_{s v r}=\frac{3 R^{2} q_{t}-\left(R^{2}+R r_{0}\right)\left(q_{n}+2 q_{t}\right)}{6} \tau \sin 2(\varphi+\pi-\beta) .
\end{array}\right.
$$

3.3. Internal Force of Tunnel under Incident $P$ Waves and Reflected $P$ Waves. This section gives the analytical solution of a circular tunnel under incident $P$ waves and reflected $P$ waves, and the pseudo-static ground-tunnel system at the local coordinate system is shown in Figure 3(a). The far-field stresses $\sigma v$ and $\sigma_{h}$ induced by incident $\mathrm{P}$ waves and reflected $\mathrm{P}$ waves are expressed by equations (3) and (4), respectively. The far-field stress of tunnel lining can be decomposed into hydrostatic pressure component and pure shear stress component, as shown in Figure 5; the hydrostatic pressure component $p$ and pure shear stress $\tau$ component are expressed in equation (24). Note that the analytical solution for the ground-tunnel system under the pure shear stress $\tau$ shown in Figure 5(c) can be obtained by equation (22), which only rotates at an angle of $\pi / 4$. Then, an analytical solution for tunnel internal force under hydrostatic pressure $p$ is derived. The model of the groundtunnel system in the local coordinate system $(\eta, \xi)$, as shown in Figure 5(b), is transformed to the polar coordinates $(\rho, \varphi)$, as shown in Figure 6(a). 


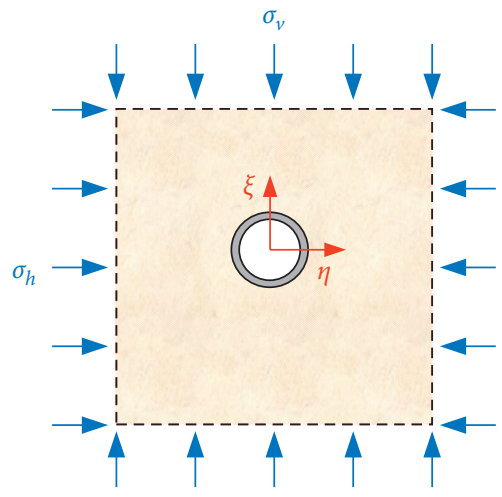

(a)

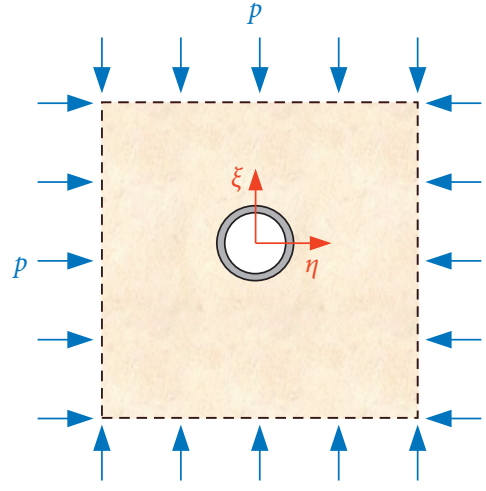

(b)

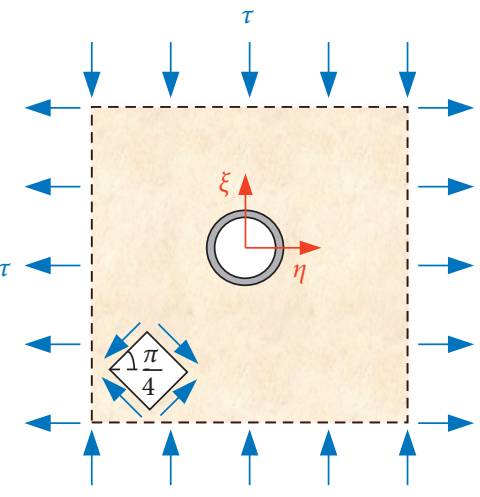

(c)

Figure 5: Force decomposition of the pseudo-static analysis model under P waves: (a) vertical stress $\sigma v$ and horizontal stress $\sigma_{h}$; (b) hydrostatic pressure component $p$; (c) pure shear stress component $\tau$.

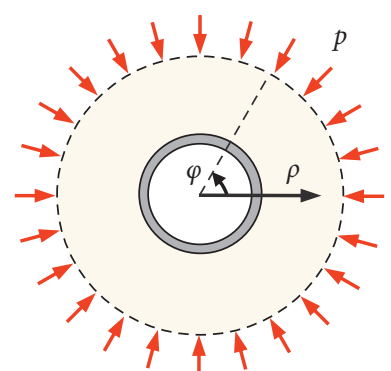

(a)

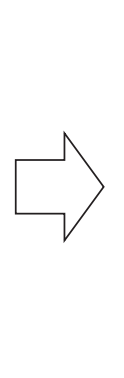

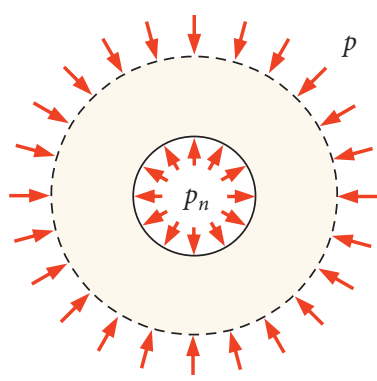

(b)

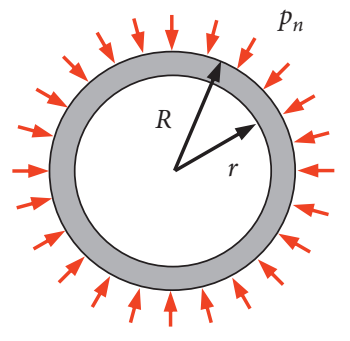

(c)

Figure 6: Decomposition of the ground-tunnel system under hydrostatic pressure component (p): (a) ground-tunnel system in polar coordinates; (b) ground system; (c) tunnel system.

$$
\left\{\begin{array}{l}
p=\frac{\left(\sigma_{v}+\sigma_{h}\right)}{2}, \\
\tau=\frac{\left(\sigma_{v}-\sigma_{h}\right)}{2} .
\end{array}\right.
$$

For the convenience of analysis, the tunnel subjected to hydrostatic pressure (Figure 6(a)) can be further decomposed into a cylindrical cavity subjected to an outward internal pressure $p_{n}$ and inward external pressure $p$ (Figure 6(b)); the tunnel lining is subjected to the inward external pressure $p_{n}$ and the inner surface is free (Figure 6(c)). At the ground and the tunnel contact interface, the stress and displacement should be satisfied:

$$
\left\{\begin{array}{l}
\left.\sigma_{\rho(g)}\right|_{\rho=R}=\left.\sigma_{\rho(l)}\right|_{\rho=R} \\
\left.u_{\rho(g)}\right|_{\rho=R}=\left.u_{\rho(l)}\right|_{\rho=R}
\end{array}\right.
$$

According to the theory of elasticity, the general solution of stress component, and displacement component under axisymmetric stress state [30], the radial and circumferential stress components are expressed as

$$
\left\{\begin{array}{l}
\sigma_{\rho}=\left(\frac{A}{\rho^{2}}+2 C\right), \\
\sigma_{\varphi}=-\left(\frac{A}{\rho^{2}}+2 C\right) .
\end{array}\right.
$$

The corresponding radial displacement component is $u_{\rho}=(n-m) \frac{A}{\rho}+2(m+n) C \rho+I \cos \varphi+K \sin \varphi$.

For the ground-tunnel system, the stress boundary condition is

$$
\left\{\begin{array}{l}
\left.\sigma_{\rho(g)}\right|_{\rho=\infty}=\frac{A_{g}}{\rho^{2}}+2 C_{g}=-p, \\
\left.\sigma_{\rho(l)}\right|_{\rho=r}=\frac{A_{l}}{r^{2}}+2 C_{l}=0 .
\end{array}\right.
$$

In the contact interface between the ground and the tunnel, the continuity conditions of stress and displacement should be satisfied. Equations (26) and (27) are substituted into equation (5); one obtains 


$$
\left\{\begin{array}{l}
\left(n_{g}-m_{g}\right) \frac{A_{g}}{R}+2\left(m_{g}+n_{g}\right) C_{g} R+I_{g} \sin \varphi+K_{g} \cos \varphi \\
=\left(n_{l}-m_{l}\right) \frac{A_{l}}{R}+2\left(m_{l}+n_{l}\right) C_{l} R+I_{l} \sin \varphi+K_{l} \cos \varphi, \\
\frac{A_{g}}{R^{2}}+2 C_{g}=\frac{A_{l}}{R^{2}}+2 C_{l} .
\end{array}\right.
$$

Equation (29) should hold for any value of $\varphi$. Substituting $\varphi$ equals $0, \pi / 2, \pi$, and $3 \pi / 2$ into equation (29), we obtain

$$
\left\{\begin{array}{l}
I_{g}=I_{l}, \\
K_{g}=K_{l} .
\end{array}\right.
$$

Equation (29) is simplified as

$$
\left\{\begin{array}{l}
\left(n_{g}-m_{g}\right) \frac{A_{g}}{R}+2\left(m_{g}+n_{g}\right) C_{g} R+\left(m_{l}-n_{l}\right) \frac{A_{l}}{R}-2\left(m_{l}+n_{l}\right) C_{l} R=0, \\
\frac{A_{g}}{R^{2}}+2 C_{g}-\frac{A_{l}}{R^{2}}-2 C_{l}=0 .
\end{array}\right.
$$

Combining equations (28) and (31) to solve the equation, the constants $A_{l}$ and $C_{l}$ can be solved as

$$
\left\{\begin{array}{l}
A_{l}=2 A^{\prime} R^{2} r^{2} \frac{\sigma_{v}+\sigma_{h}}{2} \\
C_{l}=-A^{\prime} R^{2} \frac{\sigma_{v}+\sigma_{h}}{2}
\end{array}\right.
$$

where $\quad A^{\prime}=m_{g} /\left(-m_{g}+n_{g}+m_{l}-n_{l}\right) r^{2}+\left(m_{g}-n_{g}+m_{l}+\right.$ $\left.n_{l}\right) R^{2}$

The thrust $T_{h}$ and the moment $M_{h}$ of the tunnel lining under the hydrostatic pressure $p$ can be obtained by integration:

$$
\left\{\begin{array}{l}
T_{h}=\left(\sigma_{v}+\sigma_{h}\right) A^{\prime} R\left(r^{2}-R^{2}\right), \\
M_{h}=\left(\sigma_{v}+\sigma_{h}\right) A^{\prime} R^{2} r^{2}\left(\ln \frac{r}{R}+\frac{R^{2}-r^{2}}{2 R r}\right) .
\end{array}\right.
$$

The analytical solution for the thrust $T_{p}$ and the moment $M_{p}$ of the tunnel under the $\mathrm{P}$ waves in the local coordinate system $(\eta, \xi)$ can be obtained by superposing the solution for the internal forces of the tunnel subjected to hydrostatic pressure $p$ and pure shear stress $\tau$ :

$$
\left\{\begin{array}{l}
T_{p}(\varphi)=T_{h}+T_{s v}\left(\frac{\varphi+\pi}{4}\right) \\
M_{p}(\varphi)=M_{h}+M_{s v}\left(\frac{\varphi+\pi}{4}\right)
\end{array}\right.
$$

Namely,

$$
\left\{\begin{array}{l}
T_{p}=\left(\sigma_{v}+\sigma_{h}\right) A^{\prime} R\left(r^{2}-R^{2}\right)+\frac{R}{6}\left(q_{n}+2 q_{t}\right)\left(\sigma_{v}-\sigma_{h}\right) \sin 2\left(\frac{\varphi+\pi}{4}\right) \\
M_{p}=\left(\sigma_{v}+\sigma_{h}\right) A^{\prime} R^{2} r^{2}\left(\ln \frac{r}{R}+\frac{R^{2}-r^{2}}{2 R r}\right)+\frac{3 R^{2} q_{t}-\left(R^{2}+R r\right)\left(q_{n}+2 q_{t}\right)}{12}\left(\sigma_{v}-\sigma_{h}\right) \sin 2\left(\frac{\varphi+\pi}{4}\right) .
\end{array}\right.
$$

Since the incident angle of $\mathrm{P}$ waves in the $(X, Y)$ coordinate system is $\alpha$, the analytical solution of tunnel thrust
$T_{p i}$ and moment $M_{p i}$ under incident $\mathrm{P}$ waves can be obtained from equation (35) by transforming $\varphi$ into $\varphi+\alpha$ :

$$
\left\{\begin{array}{l}
T_{p i}=\left(\sigma_{v 1}+\sigma_{h 1}\right) A^{\prime} R\left(r^{2}-R^{2}\right)+\frac{R}{6}\left(q_{n}+2 q_{t}\right)\left(\sigma_{v 1}-\sigma_{h 1}\right) \cos 2(\varphi+\alpha) \\
M_{p i}=\left(\sigma_{v 1}+\sigma_{h 1}\right) A^{\prime} R^{2} r^{2}\left(\ln \frac{r}{R}+\frac{R^{2}-r^{2}}{2 R r}\right)+\frac{3 R^{2} q_{t}-\left(R^{2}+R r\right)\left(q_{n}+2 q_{t}\right)}{12}\left(\sigma_{v 1}-\sigma_{h 1}\right) \cos 2(\varphi+\alpha)
\end{array}\right.
$$


Similar to the solution of incident $\mathrm{P}$ waves, the analytic solution for the thrust $T_{p r}$ and the moment $M_{p r}$ of tunnel under reflected $\mathrm{P}$ waves can be obtained by rotating $\pi-\alpha$ of $\varphi$ angle in equation (35):

$$
\left\{\begin{array}{l}
T_{p r}=\left(\sigma_{v 2}+\sigma_{h 2}\right) A^{\prime} R\left(r^{2}-R^{2}\right)+\frac{R}{6}\left(q_{n}+2 q_{t}\right)\left(\sigma_{v 2}-\sigma_{h 2}\right) \cos 2(\varphi-\alpha), \\
M_{p r}=\left(\sigma_{v 2}+\sigma_{h 2}\right) A^{\prime} R^{2} r^{2}\left(\ln \frac{r}{R}+\frac{R^{2}-r^{2}}{2 R r}\right)+\frac{3 R^{2} q_{t}-\left(R^{2}+R r\right)\left(q_{n}+2 q_{t}\right)}{12}\left(\sigma_{v 2}-\sigma_{h 2}\right) \cos 2(\varphi-\alpha) .
\end{array}\right.
$$

3.4. Internal Force of Tunnel under Obliquely Incident $P$ Waves. By superimposing equations (23), (36), and (37), the analytical solution for the total thrust $T$ and the moment $M$ of the tunnel under obliquely incident $\mathrm{P}$ waves can be obtained:

$$
\left\{\begin{array}{l}
T=T_{\mathrm{svr}}+T_{\mathrm{pi}}+T_{\mathrm{pr}} \\
M=M_{\mathrm{svr}}+M_{\mathrm{pi}}+M_{\mathrm{pr}}
\end{array}\right.
$$

\section{Numerical Verification of Analytical Solution}

4.1. Dynamic Time History Methodology and Parameter. In previous studies [31-34], validation works always take the numerical results by the quasi-static FE model as the reference results to assess these analytical solution. The quasistatic methodology keeps consistent with the assumptions of these analytical solution, and it does not suffer from the inherent limitations of the forced-based approach (e.g., sensitivity on the dimensions of the model). In practice, the seismic response of underground tunnels under earthquake waves is a dynamic process. Therefore, in this study, the dynamic time history methodology is employed to verify the proposed analytical solution, which can take account of the radiation damping effect and simulates the seismic wave's propagation and scattering in complex environment well.

A two-dimensional finite element model of the groundtunnel system was established by using the general finite element software ABAQUS [35]. The finite element domain has a width $W$ of $200 \mathrm{~m}$ and a height $H$ of $200 \mathrm{~m}$, as illustrated in Figure 7. The tunnel is embedded in domain with an outer radius $R$ of $3 \mathrm{~m}$. The mechanical parameters of the tunnel include density $\rho_{l}=2500 \mathrm{~kg} / \mathrm{m}^{3}$, Young's modulus $E_{l}=30 \mathrm{GPa}$, and Poisson's ratio $U_{i}=0.2$. In the study, the effect of the lining thickness $t$, buried depth $h$ of the tunnel, ground conditions, and obliquely incident angles $\alpha$ of $\mathrm{P}$ waves on the accuracy of proposed solution will be discussed, which will be introduced, respectively, for each verification case in the following sections.

Both the ground and the tunnel are simulated by linear elastic solid elements, and the finite element model is discretized according to the accuracy of numerical simulation. The mesh size of the element satisfies the requirement that the mesh size is less than $1 / 6 \sim 1 / 8$ minimum wavelength in dynamic simulation. At the ground-tunnel interface, the tangential behavior of the interface is modelled by setting equivalent springs to connect the two points on the contact surface for the arbitrary slip state. In terms of the normal contact behavior, the potential separation between the surrounding ground and the tunnel lining is not allowed.

The viscous-spring artificial boundary [36] was set at the truncated boundary of the ground to consider the dissipation effect of energy, which can be realized by establishing two pairs of dashpots and springs at the boundary node, i.e., one in the normal direction of the boundary plane and the other in the tangential directions. The spring and damping element parameters of the viscous-spring artificial boundary have the expression as [36]

$$
\left\{\begin{array}{l}
K_{N}=A_{l} \frac{1}{1+A} \frac{\lambda+2 G}{r}, \\
C_{N}=A_{l} B \rho c_{p}, \\
K_{T}=A_{l} \frac{1}{1+A} \frac{G}{r} \\
C_{T}=A_{l} B \rho c_{s},
\end{array}\right.
$$

where subscripts $N$ and $T$ represent the normal and tangent directions of the truncated boundary, respectively, $r$ can be simply taken as the distance between the geometric center of the structure and the artificial boundary node $l, \lambda, G$, and $\rho$ represent the Lame constant, shear modulus, and density of the ground, respectively, $c_{s}$ is the shear wave velocity, $c_{p}$ is the compression wave velocity, $A_{l}$ is the truncated boundary area of all elements including the boundary node $l, A$ and $B$ are correction coefficients, and the recommended values are 0.8 and 1.1 [36].

Kobe seismic record of Takatori Station in 1995 Hanshin earthquake is selected as the incident earthquake motions, whose acceleration-time history is shown in Figure 8 . The earthquake motions are transformed into nodal forces applied at the boundary nodes. The seismic-induced boundary nodal force can be expressed as

$$
\left[F_{B}\right]_{l}=A_{l} \sigma_{l}^{f}+\left[K_{B}\right]_{l} u_{l}^{f}+\left[C_{B}\right]_{l} \dot{u}_{l}^{f},
$$

where $u_{l}^{f}, \dot{u}_{l}^{f}$, and $\sigma_{l}^{f}$ are the free-field displacement, velocity, and stress on the artificial boundary node $l\left(x_{l}, y_{l}\right)$, respectively. $K_{B}$ and $C_{B}$ are the spring and damping matrices of the viscous-spring boundary. In this paper, the calculation method for the boundary nodal forces induced by obliquely incident plane $\mathrm{S}$ waves and $\mathrm{P}$ waves is referred to previous 


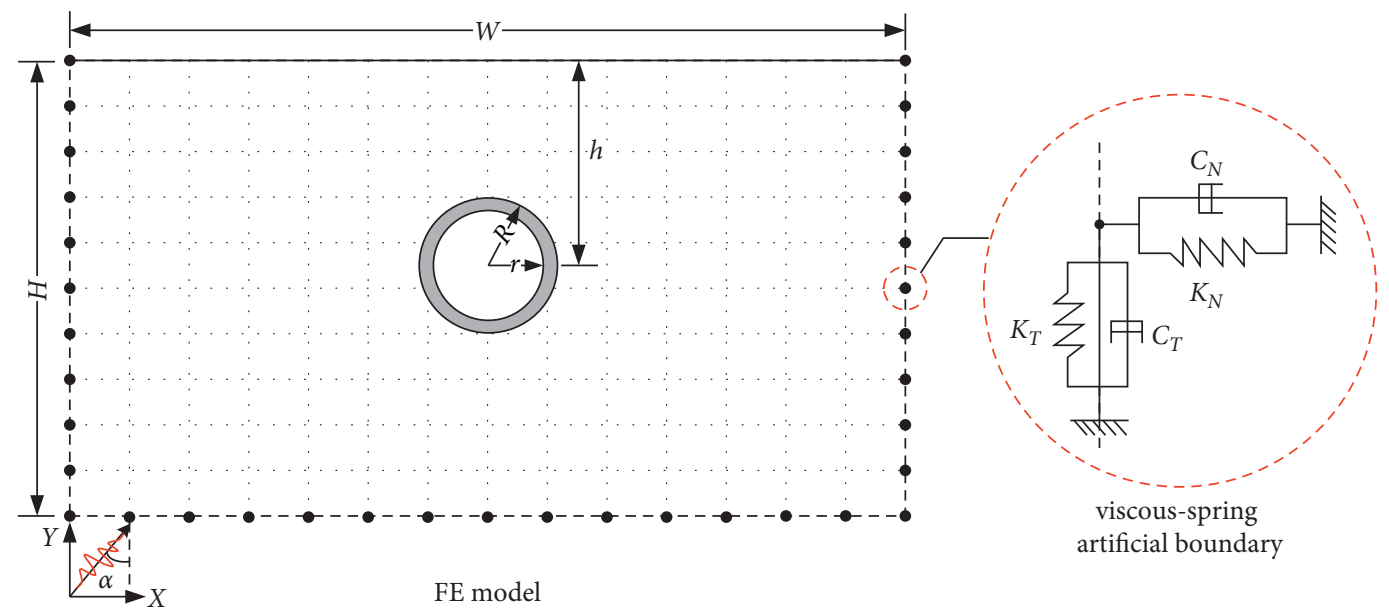

Figure 7: finite element model with viscous-spring artificial boundary.

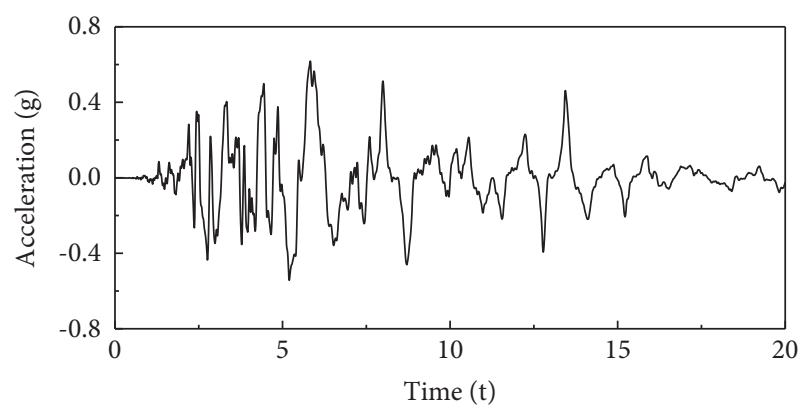

FIgURE 8: Acceleration-time history of the Kobe seismic record of Takatori Station.

works by Zhao et al. [37] and Huang et al. [15, 22]. The physical parameters of the ground and the tunnel are specified in each of the following sections.

\subsection{Verification of Solutions under $S V$ and $P$ Waves in Full-} Space. In this study, the proposed analytical solution for tunnels in half-space under obliquely incident $\mathrm{P}$ waves is the superposition of the solution for the deep tunnel in fullspace under $\mathrm{P}$ waves and SV waves. Therefore, the accuracy of the solution for the deep tunnel in full-space under $\mathrm{P}$ waves and SV waves is firstly verified. The mechanical parameters of the ground include the density $\rho_{g}=2500 \mathrm{~kg} / \mathrm{m}^{3}$, Young's modulus $E_{g}=4.5 \mathrm{GPa}$, and Poisson's ratio $v_{g}=0.25$. The effect of the lining thickness on the accuracy of proposed solution is studied here, with values of $0.3 \mathrm{~m}, 0.6 \mathrm{~m}$, and $0.9 \mathrm{~m}$, respectively. Moreover, different contact conditions at the ground-tunnel interface are also considered. The stiffness coefficient takes values of $1 e^{16}, 1 e^{8}$, and 0 , corresponding to the contact conditions of no-slip, middle-slip (midslip), and full-slip, respectively. The Kobe seismic record shown in Figure 8 is input from the model's bottom as the shear wave and compression wave, respectively.

To comprehensively consider the relative error between the analytical solution results and the numerical results at each data point, the error $E$ is defined as follows:

$$
E=\frac{\|X-Y\|^{2}}{\|Y\|^{2}}=\frac{\sqrt{\sum_{i=1}^{n}\left|x_{i}-y_{i}\right|^{2}}}{\sqrt{\sum_{i=1}^{n}\left|y_{i}\right|^{2}}},
$$

where $x_{i}$ represents the result of the analytical solution at the $i$ th monitoring point of the lining cross section, $y_{i}$ represents the numerical result at the $i$ th monitoring point, and $n$ represents the number of monitoring points.

Figures 9 and 10, respectively, show the distributions of the peak thrust $T_{\max }$ and the peak moment $M_{\max }$ along the cross section of the tunnel under SV waves and $\mathrm{P}$ waves using the new analytical solution, the widely used Bobet's solution [11, 12], and the dynamic numerical solution. As Bobet's solution can only consider the no-slip and full-slip conditions, the result of Bobet's solution at midslip is not offered.

From Figures 9 and 10, it can be found that the thrust and the moment have the same distribution form along the cross section of the tunnel. For SV waves, the thrust and the moment get their maximum at the spandrel and the arch foot. However, while for $\mathrm{P}$ waves, these two internal forces get their maximum value at the haunches. Whether for $\mathrm{P}$ or SV waves, the new analytical solution results are in good agreement with the numerical results for different contact conditions and different lining thicknesses. Although, in some cases, the proposed analytical solution and Bobet's solution are very close to each other, in many cases, the proposed analytical solution performs far better than Bobet's solution, especially for tunnels with very thick lining. This is why the tunnel is considered a thick-wall cylinder rather than a beam or shell, which makes the accuracy of the proposed analytical solution not affected by the lining thickness.

\subsection{Verification of Solutions under Obliquely Incident $P$ Waves} in Half-Space. This section verifies the accuracy and applicability of the new analytical solution for the internal forces of the tunnel under obliquely incident $\mathrm{P}$ waves in a half-space. In order to study the influence of different ground conditions on the accuracy of the new analytical 

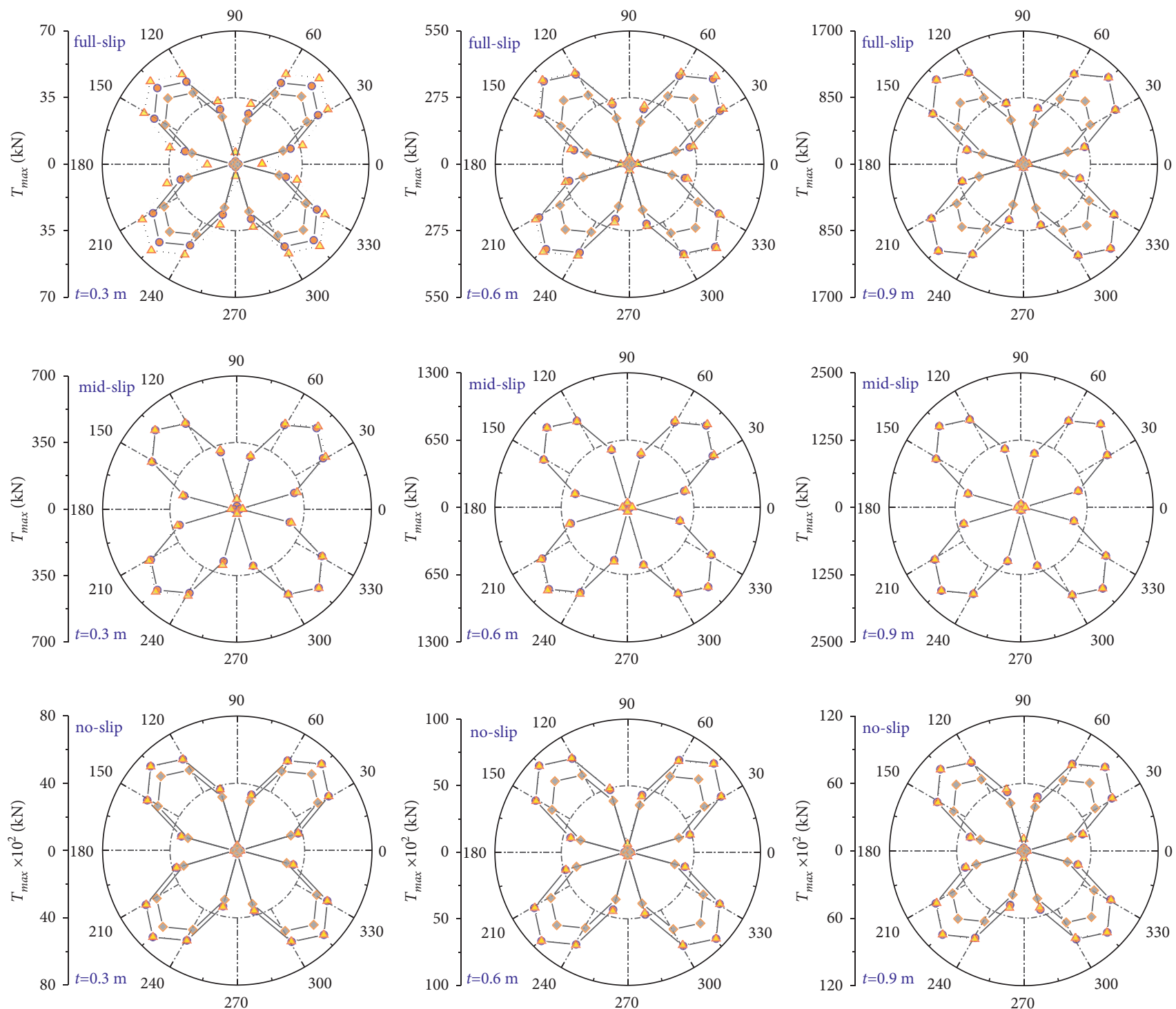

$$
\begin{aligned}
& -\bullet-\text { New } \\
& -\diamond-\text { Bobet } \\
& \therefore \Delta \cdot \text { FEM }
\end{aligned}
$$

(a)

Figure 9: Continued. 

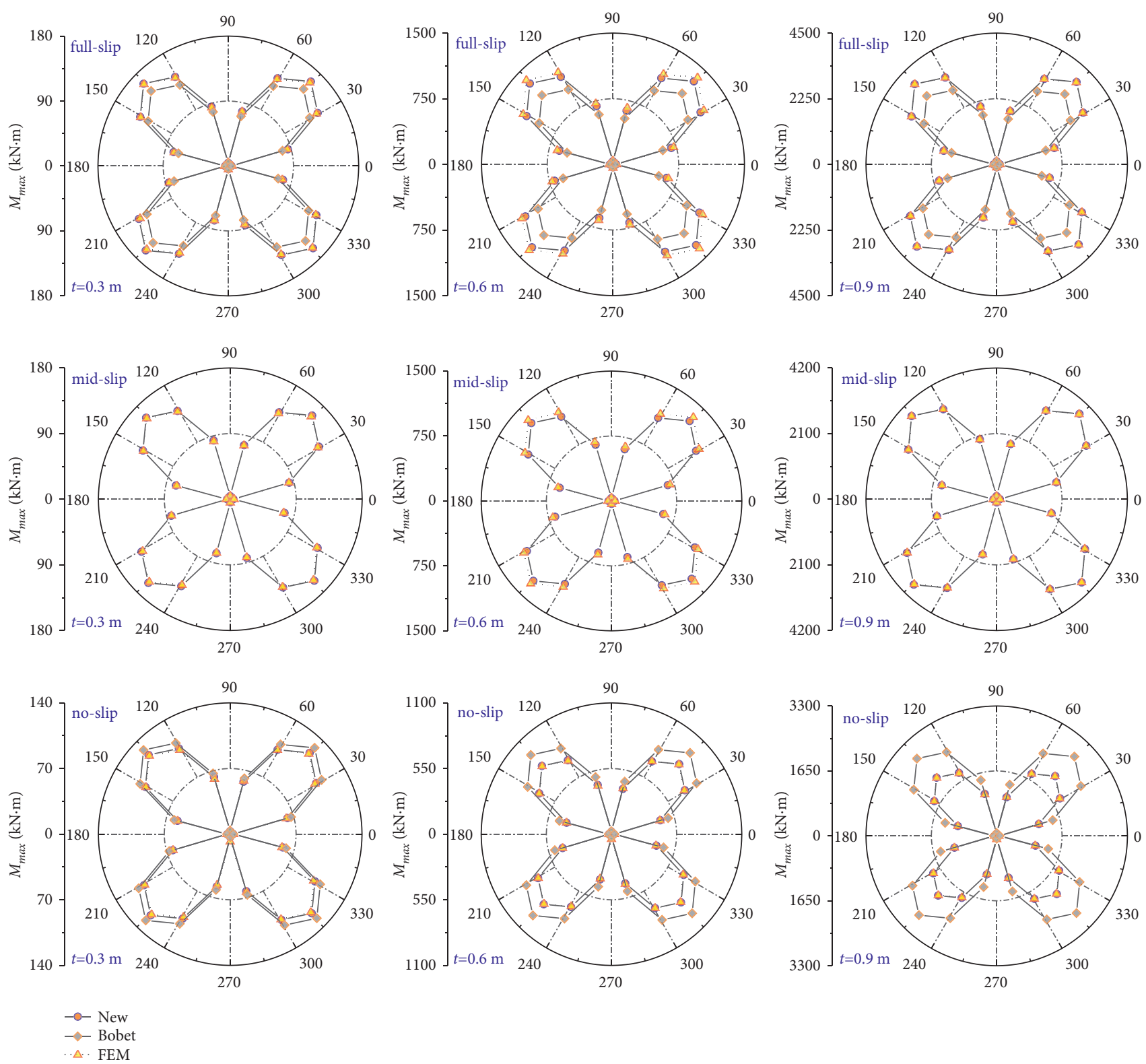

(b)

Figure 9: Distribution of (a) peak thrust $T_{\max }$ and (b) peak moment $M_{\max }$ in the full-space tunnel under SV waves considering different contact conditions and lining thickness.

solution, three ground conditions of soft soil, medium stiff soil, and rock were selected by referring to Seismic Design of Urban Rail Transit Structures (GB50909-2014) [38]. The ground physical parameters are shown in Table 1 . The outer radius of the tunnel is $R=3 \mathrm{~m}$, the thickness $t$ is $0.3 \mathrm{~m}$, and the physical parameters of the lining are the same as Section 4.1. The contact condition between the ground and the tunnel is set as no-slip condition. The Kobe seismic record, as shown in Figure 8, is used as the compression wave, which is inputted with the angle of $\alpha=0^{\circ}, 30^{\circ}, 45^{\circ}$, and $60^{\circ}$, respectively.

Figure 11 shows the distribution of peak thrust $T_{\max }$ and peak moment $M_{\max }$ along the tunnel's cross section, with considering different incident angles and ground conditions. It can be seen from Figure 11 that the peak thrust $T_{\max }$ and peak moment $M_{\max }$ by the new analytical solution and numerical solution under obliquely incident $\mathrm{P}$ waves are very close to each other. According to the above analysis, the new analytical solution can accurately predict the thrust and the moment of the tunnel under obliquely incident $\mathrm{P}$ waves and is suitable for different ground and different lining thickness.

The analytical solution for the internal force of the tunnel in the half-space under the obliquely incident $\mathrm{P}$ waves is obtained by superimposing the analytical solution for the internal force of the tunnel in the full-space. Moreover, Park et al. [8] and Bobet [11] pointed out that the analytical solution is based on the 

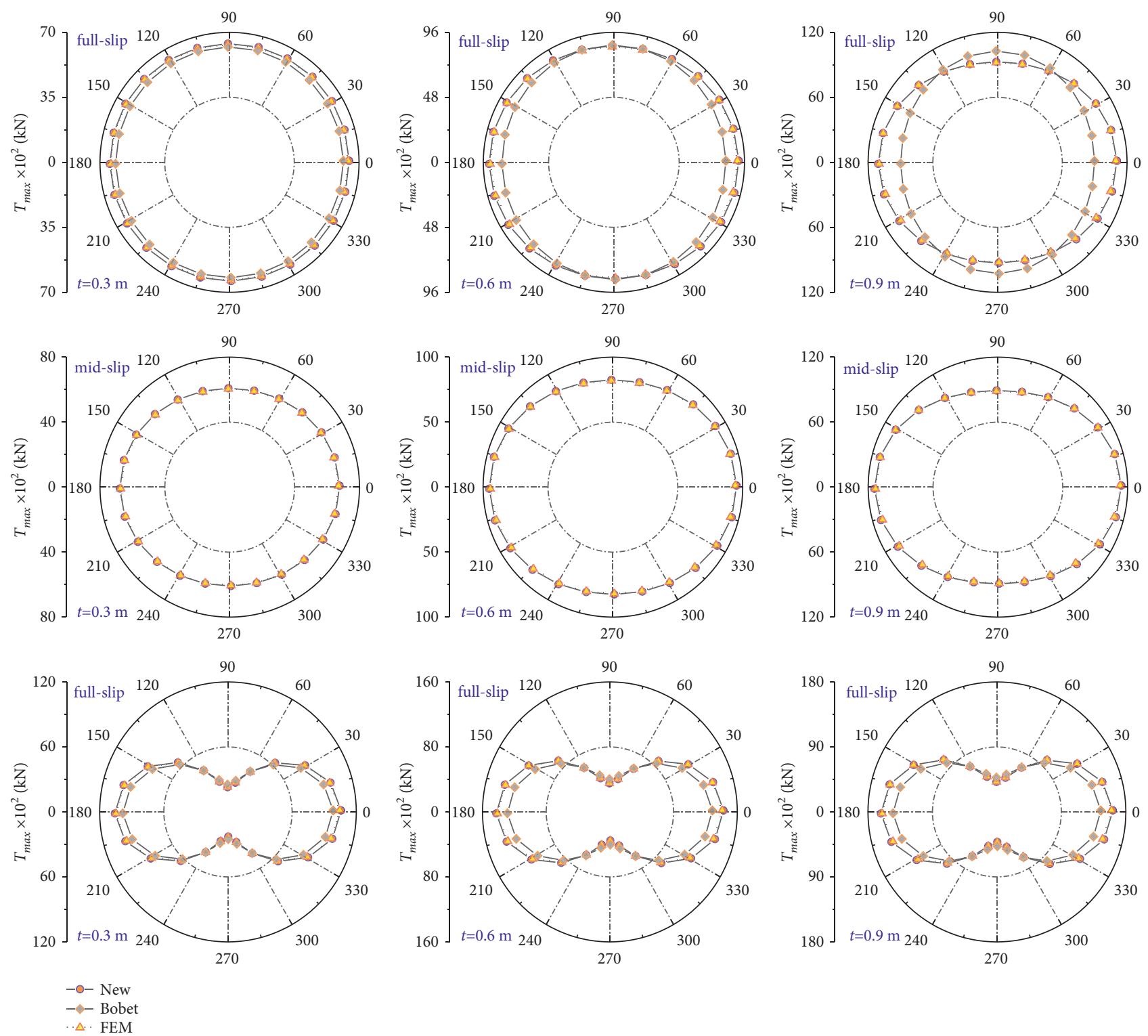

(a)

Figure 10: Continued. 

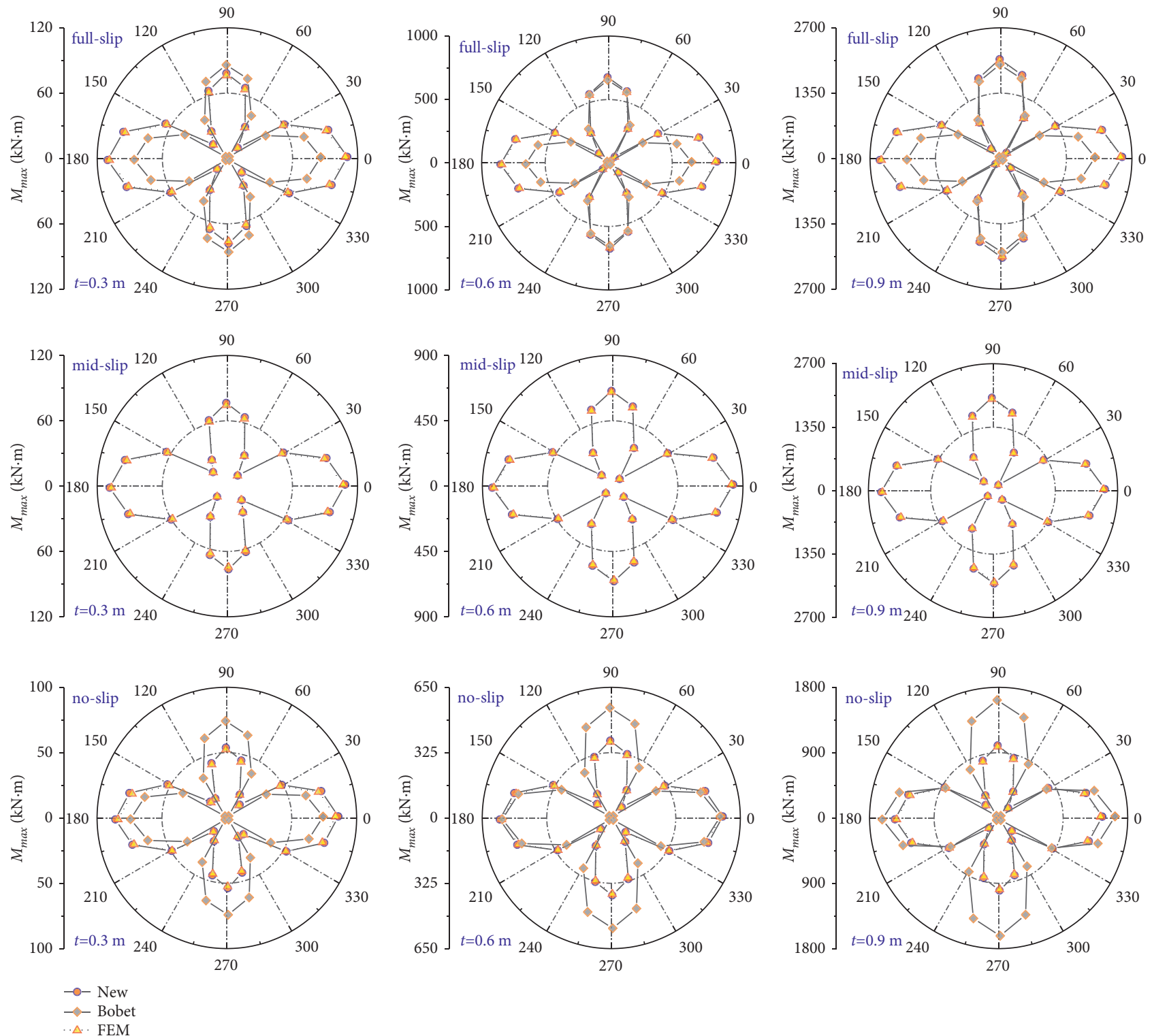

(b)

Figure 10: Distribution of (a) peak thrust $T_{\max }$ and (b) peak moment $M_{\max }$ of the tunnel in full-space under P waves considering different contact conditions and lining thickness.

condition that the buried depth of the tunnel is greater than $2 R$. Therefore, it is necessary to discuss the applicability of the new analytical solution under different buried depths. The dynamic time history analysis Method described in Section 4.1 is used as the exact solution. The buried depth $h$ of the model is set to $6 \mathrm{~m}$, $9 \mathrm{~m}, 12 \mathrm{~m}, 15 \mathrm{~m}, 20 \mathrm{~m}, 30 \mathrm{~m}, 40 \mathrm{~m}$, and $50 \mathrm{~m}$, and the incident angles $\alpha$ of the $\mathrm{P}$ waves are set to $0^{\circ}$ and $30^{\circ}$. The errors $E(\%)$ of the new analytical solution for the thrust and moment under different depth ratios $h / R$ and different ground conditions are shown in Table 2.

It can be obtained from Table 2 that the error of analytical solution decreases with the increase of $h / R$, which shows that the influence of free surface boundary condition at the top of the ground on the tunnel is weakened. When the buried depth is 4 times greater than the tunnel radius, the error of the analytical solution is less than $15 \%$.

Figure 12 shows the effect of buried depth on thrust and moment of tunnels. One can clearly observe that, as the buried depth increases, there is a most dangerous buried depth which causes the maximum internal force of the tunnel. Moreover, as the ground changes from soft ground to hard ground (Case 1 to Case 3), the most dangerous buried depth increases. It can be noted that even for soft soil ground, the most dangerous buried depth is more than $50 \mathrm{~m}$, which is 16 times greater than the tunnel radius. Therefore, the analytical solution's accuracy at the most dangerous buried depth can meet the engineering requirements, as shown in Table 2. 
TABLE 1: Physical parameters of the ground.

\begin{tabular}{|c|c|c|c|c|}
\hline Ground cases & $\begin{array}{l}\text { Density } \rho_{g} \\
\left(\mathrm{~kg} / \mathrm{m}^{3}\right)\end{array}$ & $\begin{array}{l}\text { Young's modulus } E_{g} \\
(\mathrm{MPa})\end{array}$ & Poisson's ratio $\nu_{g}$ & $\begin{array}{l}\text { Shear velocity } c_{s} \\
(\mathrm{~m} / \mathrm{s})\end{array}$ \\
\hline Case 1: soft soil $\left(c_{s} \leq 150 \mathrm{~m} / \mathrm{s}\right)$ & 2000 & 54 & 0.35 & 100 \\
\hline $\begin{array}{l}\text { Case 2: medium stiff soil }\left(250 \mathrm{~m} / \mathrm{s}<c_{s} \leq 500 \mathrm{~m} /\right. \\
\mathrm{s})\end{array}$ & 2300 & 900 & 0.3 & 388 \\
\hline Case 3: rock $\left(800 \mathrm{~m} / \mathrm{s}<c_{s}\right)$ & 2500 & 4500 & 0.25 & 848.5 \\
\hline
\end{tabular}
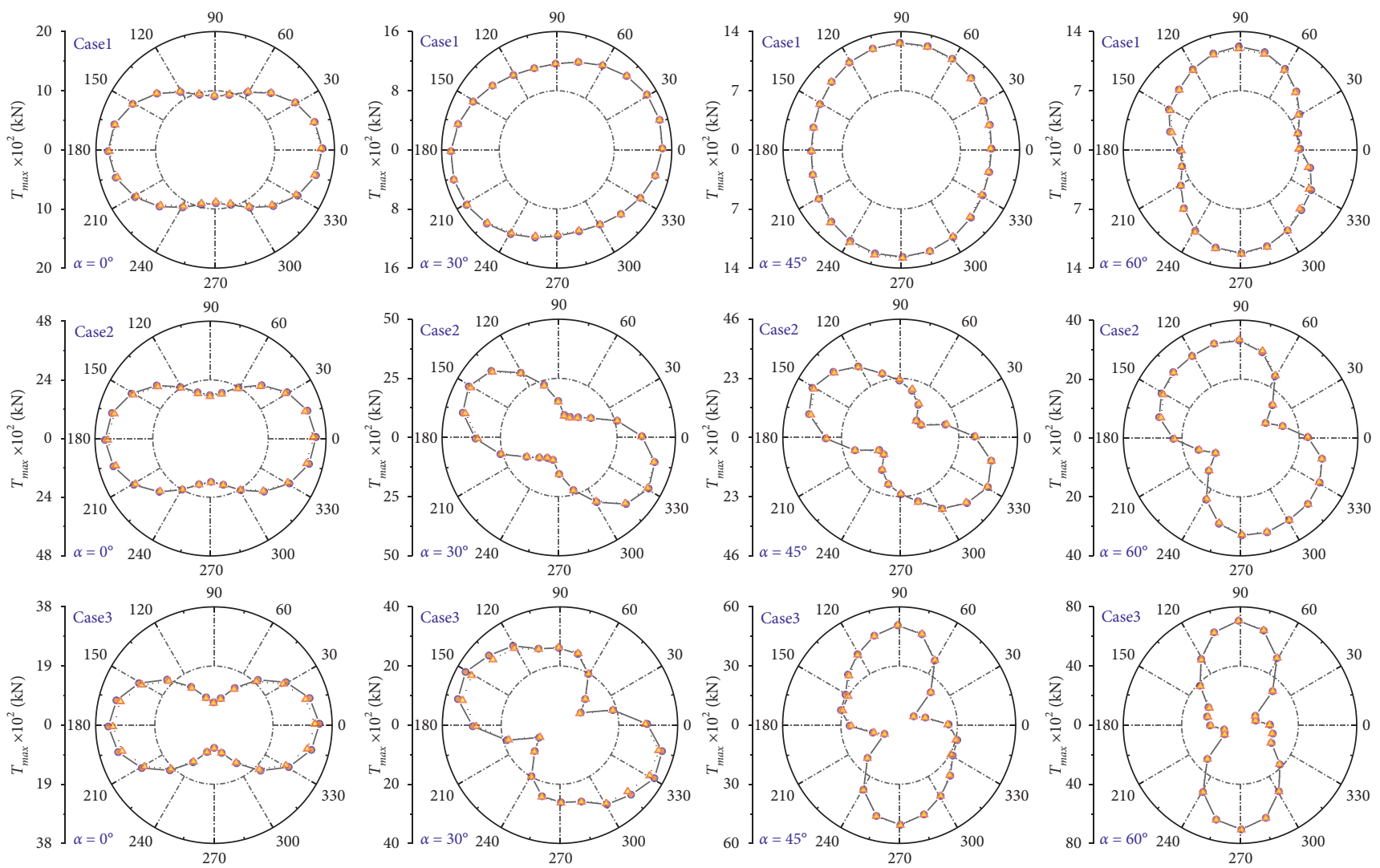

-o- New

$\triangle$. FEM

(a)

FIgUre 11: Continued. 

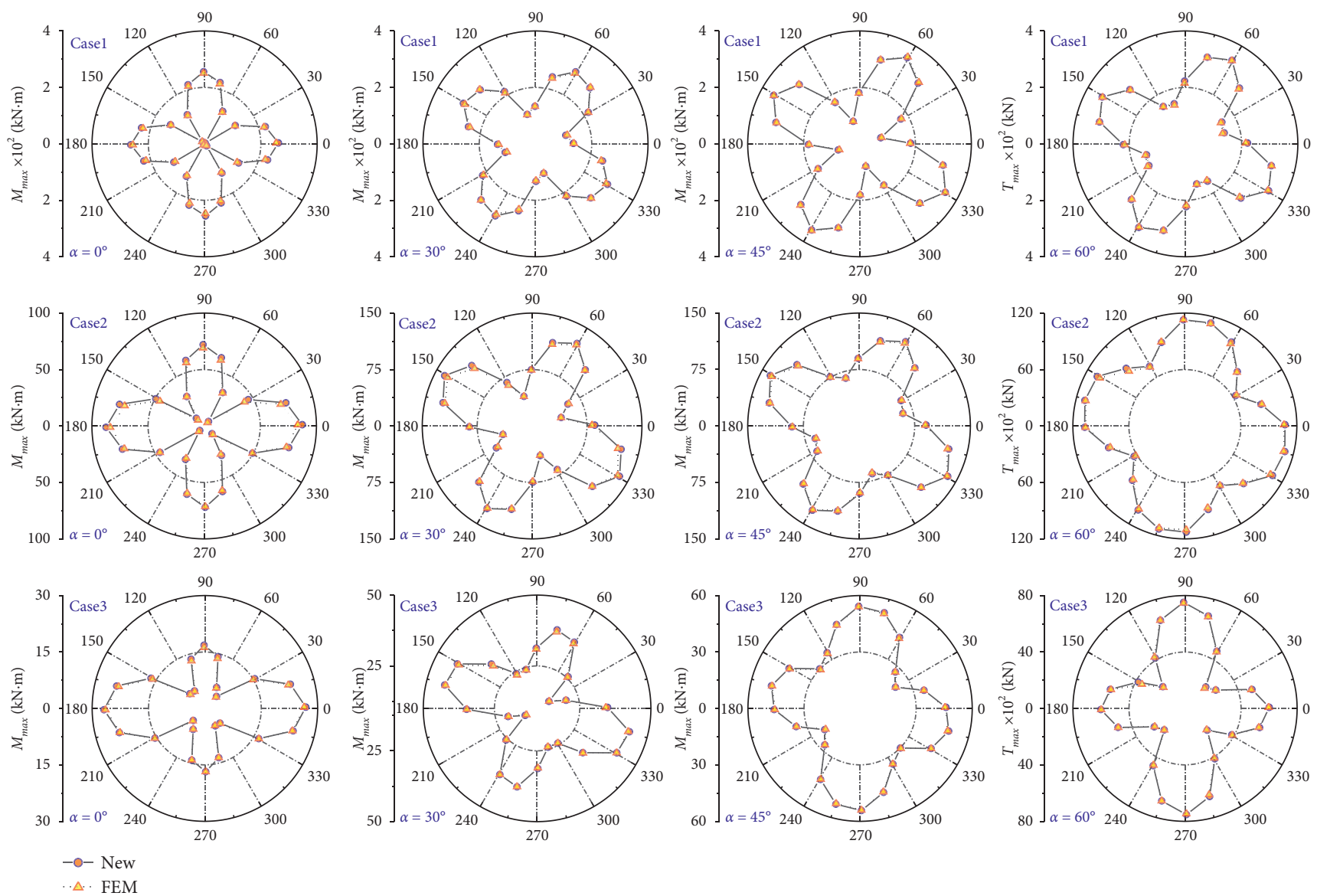

(b)

Figure 11: Distribution of (a) peak thrust $T_{\max }$ and (b) peak moment $M_{\max }$ of the tunnel in half-space under obliquely incident $\mathrm{P}$ waves with considering different incident angles and ground conditions.

\section{Discussion of Critical Factors}

5.1. Effect of Incident Angle of $P$ Waves. In this section, the effect of the incident angle of $\mathrm{P}$ waves on the seismic response of the tunnel is discussed, considering different ground conditions. The incident angles $\alpha$ takes values of $0^{\circ}$, $15^{\circ}, 30^{\circ}, 45^{\circ}, 60^{\circ}, 75^{\circ}$, and $85^{\circ}$. Three ground cases are selected, whose physical parameters are listed in Table 1. Figures 9 and 10 show that the thickness of the lining has little influence on the distribution of the tunnel's internal force under the obliquely incident $\mathrm{P}$ waves. Referring to the parameters adopted in previous studies [8, 31, 33], the thickness of lining used in the parameter analysis part is $0.3 \mathrm{~m}$. The tunnel's buried depth $h$ is $50 \mathrm{~m}$. Moreover, no-slip contact condition at the ground-tunnel interface is used. Other physical parameters of the tunnel are the same as those in Section 4.3.

Figure 13 shows the distribution of the peak thrust and peak moment along the tunnel's cross section considering different incident angles. To keep the figure concise, only $0^{\circ}$, $30^{\circ}, 60^{\circ}$, and $85^{\circ}$ are plotted. It can be found that the incident angle of $\mathrm{P}$ waves has great influence on the distribution of the thrust and moment along the tunnel's cross section. In detail, for the vertically incident case with $\alpha=0^{\circ}$, the tunnel haunches suffer the largest thrust and moment. With increasing the incident angle $\alpha$ from $0^{\circ}$ to $85^{\circ}$, the critical position for the thrust and moment has the trend of moving from the haunches to the vault and arch bottom. The larger the incident angle is, the closer to the vault and arch bottom the critical position is. Moreover, the ground conditions also have effect on the distribution of the thrust and moment of tunnels under obliquely incident angle. For a given oblique angle, the critical position is getting closer to the vault and arch bottom, as the ground changing from soft ground (ground Case 1) to hard ground (ground Case 3).

To evaluate the effect of the incident angle on the amplitude of the thrust and the moment of the tunnel, the maximum of the thrust and moment along the tunnel's cross section is plotted in Figure 14, considering different incident angles and ground conditions. From Figure 14, one can find that the maximum thrust that the tunnel suffers decrease with the increase of the incident angle for soft ground (ground Case 1). However, for hard ground (ground Case 2 and Case 3), the maximum thrust increases first and decreases with the incidence angle subsequently. The maximum moment increases first and then decreases with the incident angle for all ground conditions. From the analysis above, one can find that there is a most unfavorable incident 
TABLE 2: Error index $E$ (\%) for tunnel thrust and moment in half-space under obliquely incident $\mathrm{P}$ waves considering different buried depths and ground conditions.

\begin{tabular}{|c|c|c|c|c|c|c|c|c|c|c|c|c|}
\hline \multirow{3}{*}{$h / R$} & \multicolumn{4}{|c|}{ Case 1 (soft soil) } & \multicolumn{4}{|c|}{ Case 2 (medium stiff soil) } & \multicolumn{4}{|c|}{ Case 3 (rock) } \\
\hline & \multicolumn{2}{|c|}{$0^{\circ}$} & \multicolumn{2}{|c|}{30} & \multicolumn{2}{|c|}{$0^{\circ}$} & \multicolumn{2}{|c|}{$30^{\circ}$} & \multicolumn{2}{|c|}{$0^{\circ}$} & \multicolumn{2}{|c|}{$30^{\circ}$} \\
\hline & $T$ & $M$ & $T$ & $M$ & $T$ & $M$ & $T$ & $M$ & $T$ & $M$ & $T$ & $M$ \\
\hline 2.0 & 31.59 & 36.49 & 15.61 & 7.44 & 27.55 & 27.55 & 11.8 & 10.73 & 27.55 & 18.56 & 7.76 & 13.25 \\
\hline 3.0 & 16.54 & 22.68 & 11.45 & 7.25 & 15.40 & 15.40 & 4.79 & 5.56 & 15.40 & 14.73 & 5.32 & 6.36 \\
\hline 4.0 & 10.74 & 13.71 & 8.81 & 7.05 & 10.64 & 10.64 & 3.84 & 4.53 & 10.64 & 9.80 & 4.50 & 5.75 \\
\hline 5.0 & 8.77 & 11.39 & 7.54 & 6.77 & 8.09 & 8.09 & 3.36 & 4.30 & 8.09 & 9.69 & 4.37 & 4.82 \\
\hline 6.7 & 6.14 & 7.29 & 6.38 & 6.10 & 5.68 & 5.68 & 2.95 & 4.13 & 5.68 & 7.49 & 4.25 & 4.75 \\
\hline 10.0 & 3.27 & 3.25 & 5.12 & 5.64 & 3.64 & 3.64 & 2.67 & 3.85 & 3.64 & 5.05 & 4.20 & 4.66 \\
\hline 13.3 & 1.89 & 2.15 & 3.99 & 5.05 & 2.61 & 2.61 & 2.55 & 3.62 & 2.61 & 3.71 & 4.11 & 3.78 \\
\hline 16.7 & 1.28 & 1.82 & 2.58 & 4.64 & 1.92 & 1.92 & 2.49 & 3.55 & 1.92 & 3.05 & 3.97 & 3.48 \\
\hline
\end{tabular}
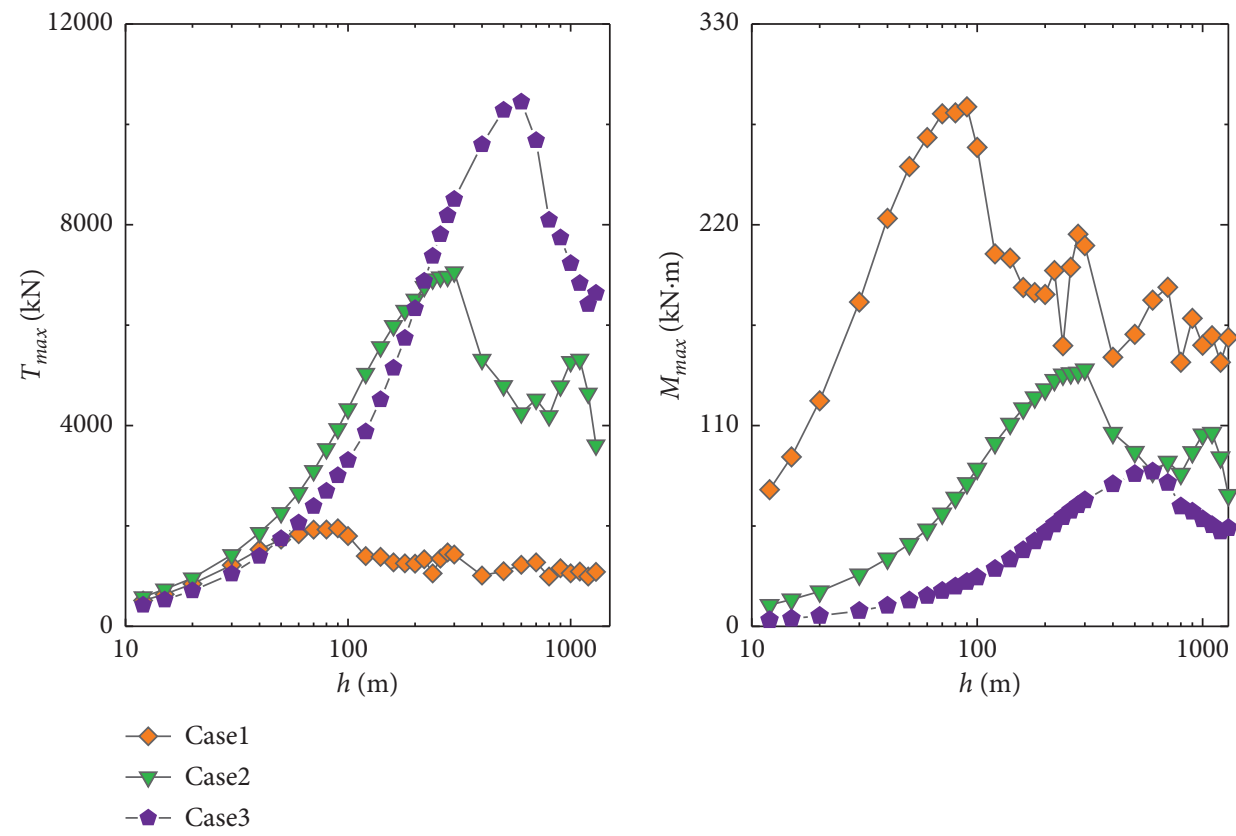

(a)
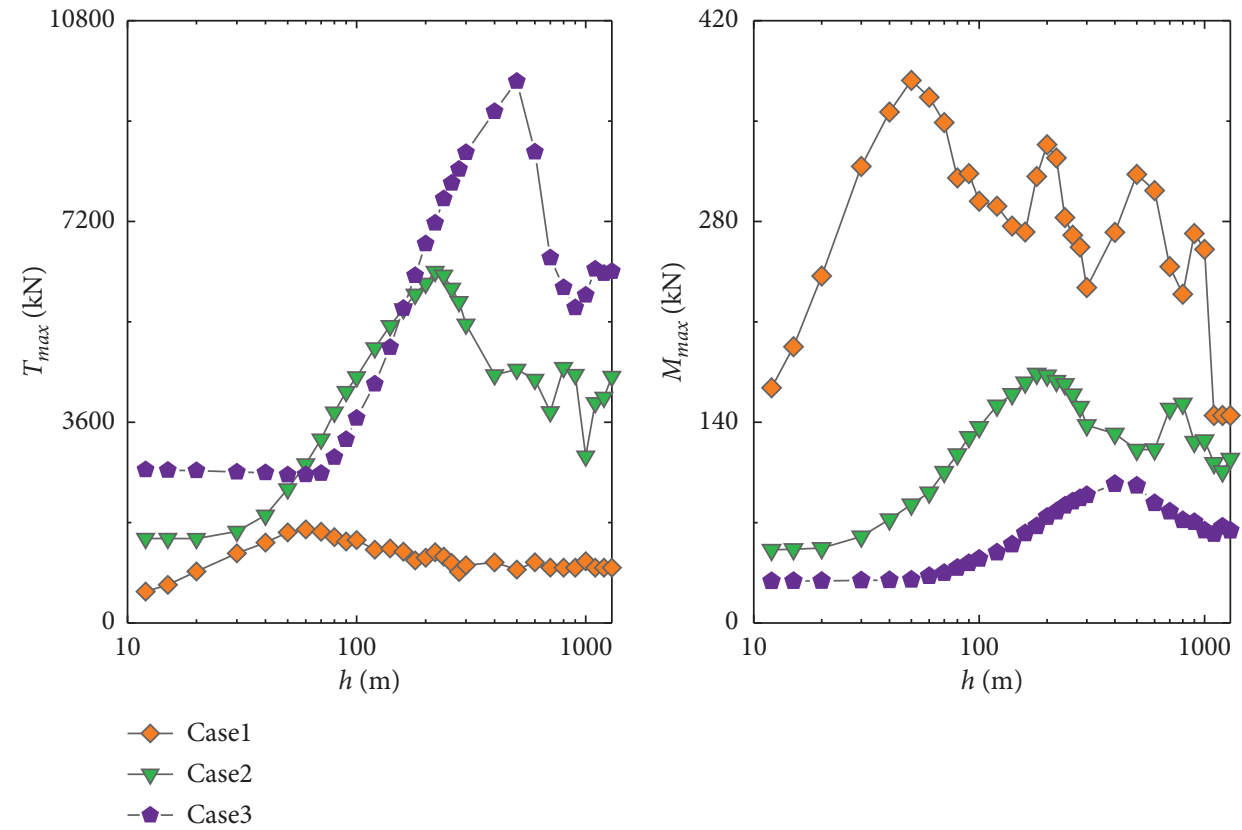

(b)

Figure 12: Effect of buried depth on thrust and moment of tunnel. (a) $\mathrm{P}$ waves' incident angle is $0^{\circ}$. (b) $\mathrm{P}$ waves' incident angle is $30^{\circ}$. 

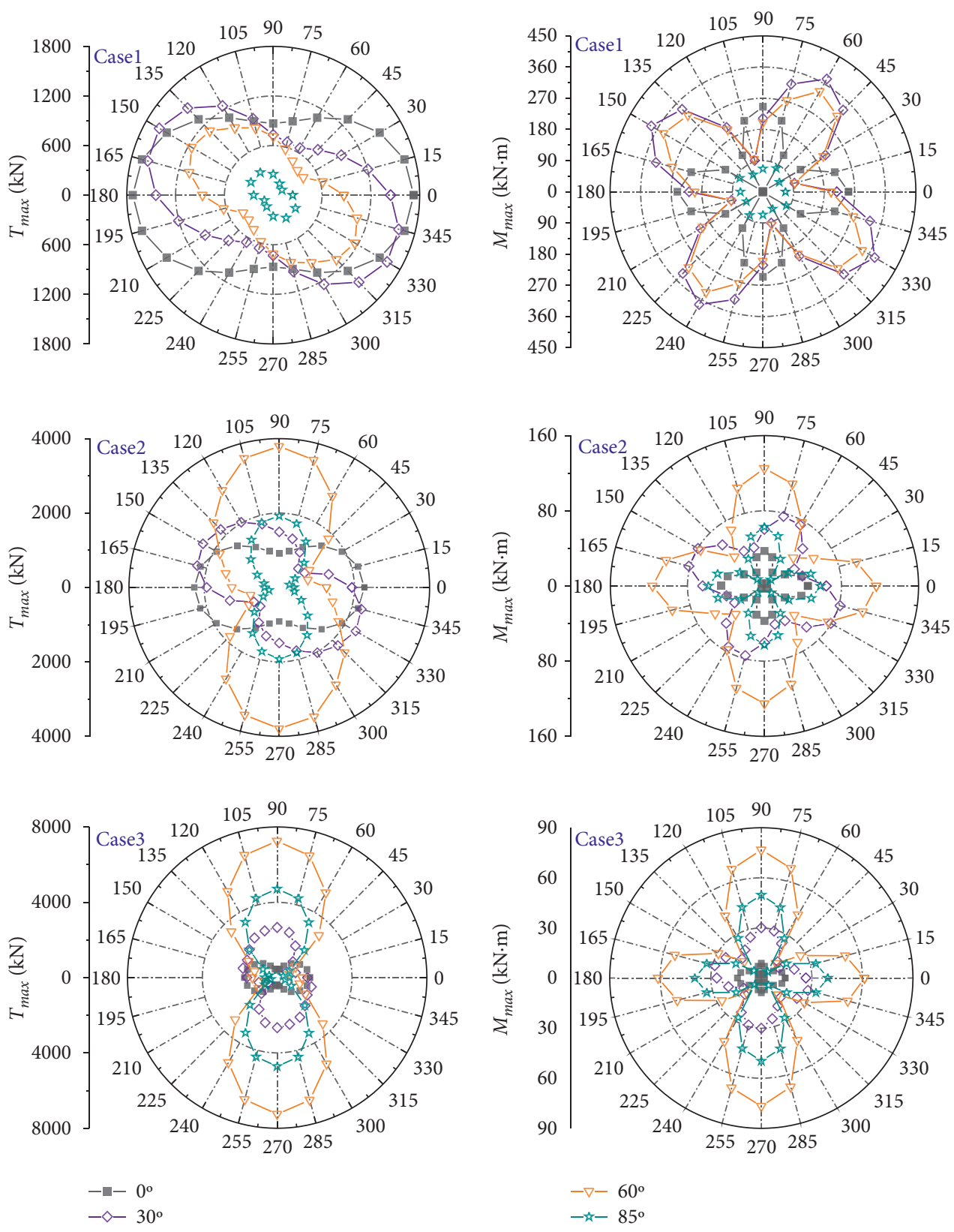

FIgURE 13: Distribution of peak thrust $T_{\max }$ and peak moment $M_{\max }$ considering different incident angles and ground conditions.

angle where the tunnel suffers the largest thrust or largest moment. Moreover, the most unfavorable incident angle becomes larger as the ground changes from soft ground to hard ground.

5.2. Effect of the Tangential Contact Stiffness at the GroundTunnel Interface. In this study, the stiffness coefficient $k$ is introduced to simulate the tangential contact stiffness at the ground-tunnel interface. In this section, the influence of the stiffness coefficient $k$ on the normalized thrust and moment is studied. The physical parameters and dimensions of the ground and tunnel are the same as those of Section 5.1.

Figure 15 shows the variation of normalized thrust and moment with the stiffness coefficient $k$ under three ground conditions. It can be found that when $k$ changes from fullslip to no-slip, the normalized thrust increases with the increase of $k$, and the normalized moment decreases with the increase of $k$. Theoretically, the influence range of $k$ is $0-\infty$. However, it can be seen from Figure 15 that the stiffness coefficient has an apparent effective influence range, but outside the effective influence range, it has little influence on the thrust and moment. Moreover, the influence range of $k$ is different under different ground conditions. As the ground changes from soft to hard, the influence range of the stiffness coefficient gradually expands.

5.3. Effect of the Relative Stiffness between the Ground and the Tunnel. As we all know, the seismic response of the underground structures depends on the ground deformation 

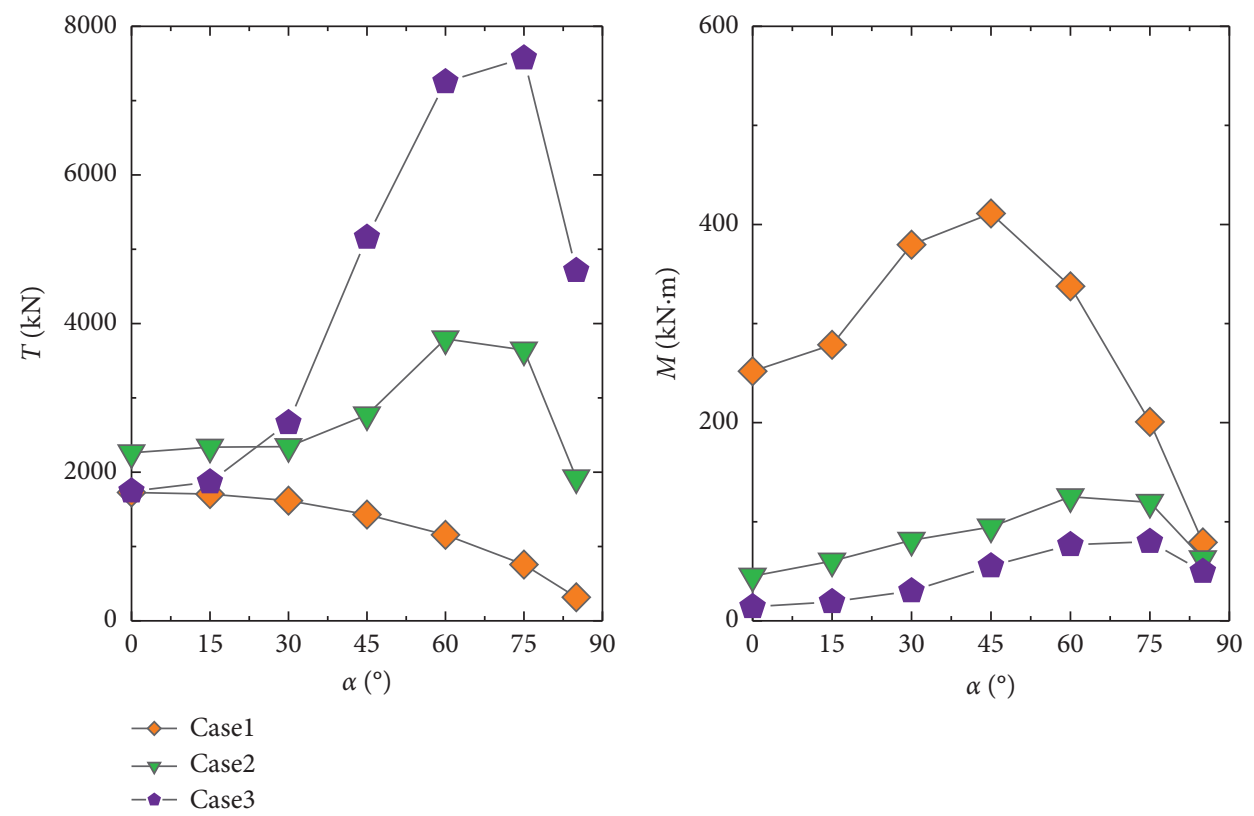

Figure 14: Extreme values of thrust and moment of tunnel considering different incident angles and ground conditions.
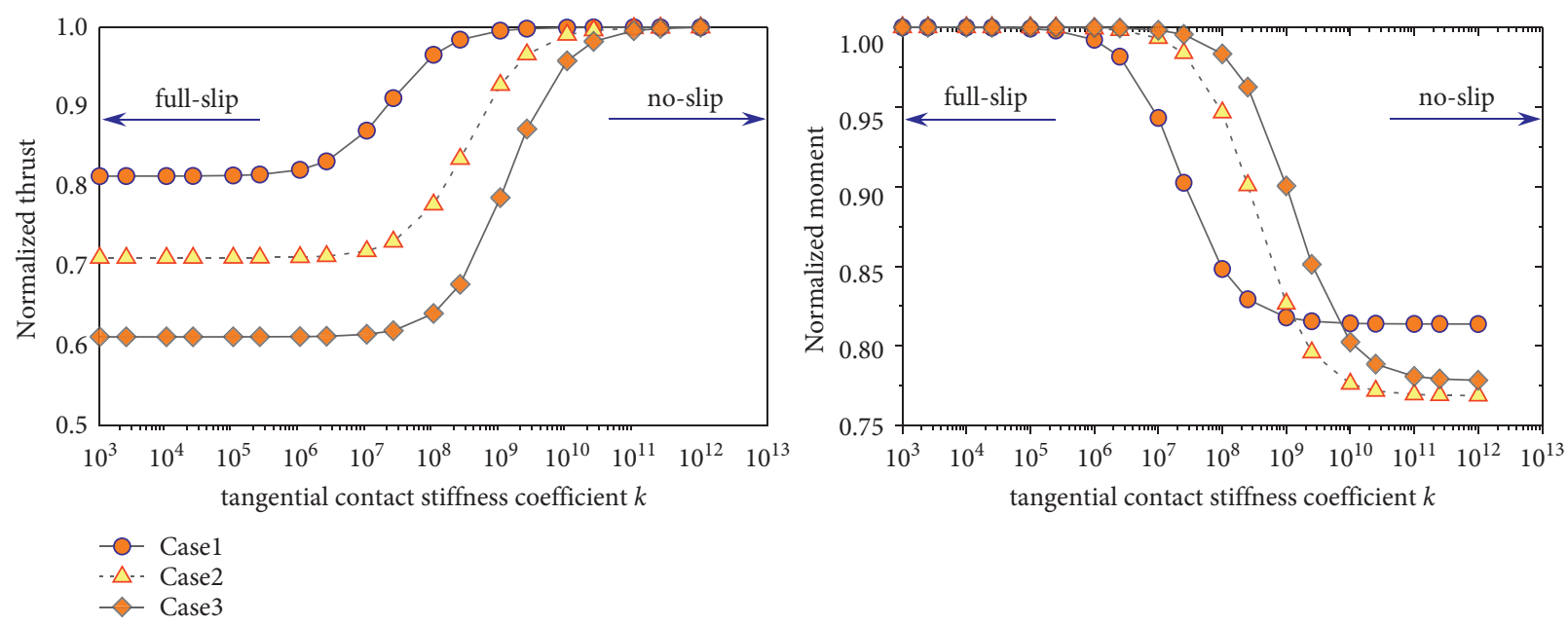

FIGURE 15: Effect of $k$ on normalized thrust and moment distribution under different ground conditions.

and the relative stiffness between the ground and the structure. In this section, the effect of the relative stiffness between the ground and the tunnel on the seismic response of the tunnel is studied. The flexibility ratio $F$ proposed by Peck et al. [39] is employed to represent the relative stiffness, which was defined as

$$
F=\frac{E_{g}\left(1-v_{l}^{2}\right) R^{3}}{6 E_{l} I\left(1+v_{g}\right)},
$$

where $E_{g}$ and $\nu_{g}$, and $E_{l}$ and $\nu_{l}$, are Young's modulus and Poisson's ratio of the ground and tunnel, respectively, and $I$ and $R$ are the moment of inertia and the outer radius of the tunnel, respectively.

Values of the flexibility ratio $F$ with values over 1 suggest that the tunnel lining has the lower stiffness with the surrounding ground. The tunnel lining and incident earthquake intensity are fixed, while Young's modulus of the ground is varied parametrically for capturing a wide range of flexibility ratios $F$. In other words, the seismic response of a tunnel under a certain earthquake exciting is studied, which is located under different ground conditions. The ground parameters are shown in Table 3 , and the corresponding flexibility ratio ranges from 0.1 to 1000 . Other parameters, such as the size, depth, and physical parameters of the tunnel, keep step with Section 5.1. Moreover, different contact conditions are considered, i.e., no-slip, midslip, and full-slip, respectively.

Figure 16 shows the effect of the flexibility ratio on the peak thrust and peak moment of the tunnel considering different contact conditions. With the increase of the flexibility ratio, as shown in Figure 16, the internal forces of the 
TABLE 3: Physical parameters of the ground and corresponding flexibility ratio.

\begin{tabular}{lccc}
\hline Density, $\rho\left(\mathrm{kg} / \mathrm{m}^{3}\right)$ & Poisson's ratio, $v$ & Young's modulus, $E_{g}(\mathrm{MPa})$ & Flexibility ratio, $F$ \\
\hline 2500 & 0.25 & 1.953 & 0.1 \\
2500 & 0.25 & 7.813 & 0.4 \\
2500 & 0.25 & 19.531 & 1 \\
2500 & 0.25 & 48.828 & 2.5 \\
2500 & 0.25 & 117.188 & 6 \\
2500 & 0.25 & 195.313 & 10 \\
2500 & 0.25 & 585.937 & 30 \\
2500 & 0.25 & 1367.188 & 70 \\
2500 & 0.25 & 1953.125 & 100 \\
2500 & 0.25 & 3906.250 & 200 \\
2500 & 0.25 & 9765.625 & 500 \\
2500 & 0.25 & 19531.25 & 1000 \\
\hline
\end{tabular}
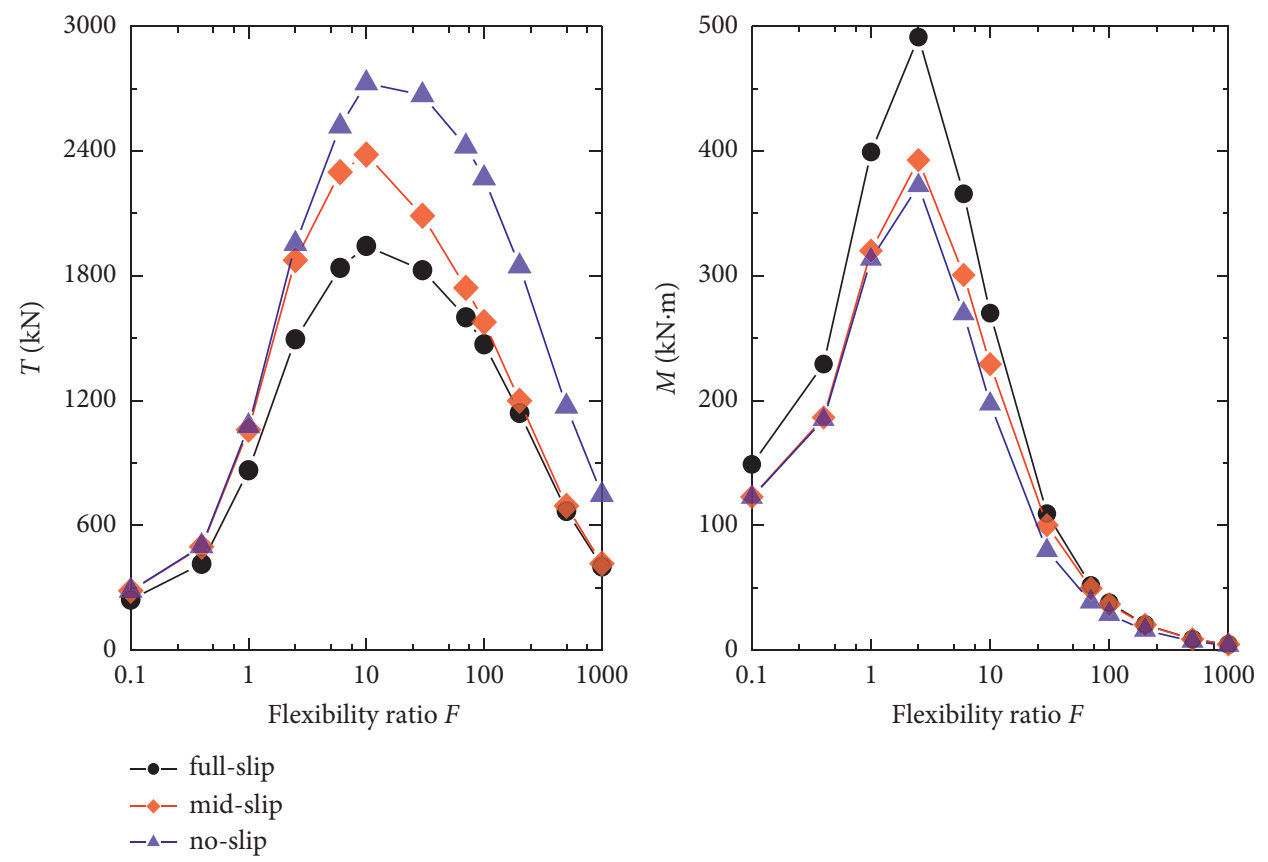

Figure 16: Peak thrust and peak moment of tunnel considering different contact conditions and flexibility ratio.

tunnel lining increase first and then decrease. That is to say, there is a most unfavorable flexibility ratio where the tunnel suffers the largest thrust or the largest moment. It should be noticed that the most unfavorable flexibility ratio for the thrust is larger than that for the moment. Moreover, the contact conditions have little effect on the value of the most unfavorable flexibility ratio.

\section{Conclusions}

In this study, an analytical solution for the seismic-induced internal forces of the circular tunnel in half-space, which is subjected to obliquely incident $\mathrm{P}$ waves, is developed. The new analytical solution is different from other previous analytical solution in three respects. (1) Previous analytical solutions were mainly developed for the tunnel's internal force under vertically incident shear waves, while the new analytical solution is for the tunnel's internal force under obliquely incident P waves in half-space. (2) Different from previous analytical solutions that regarded the tunnel lining as a beam or a shell, the new solution treats the tunnel lining as a thick-wall cylinder, which can provide more precise predictions than beam or shell models used in previous analytical solutions, especially for tunnels with thick lining. (3) Most of previous solution only consider the full-slip and no-slip contact states at the ground-tunnel interface. In this study, a spring-type stiffness coefficient is introduced to consider the arbitrary contact state of the ground-tunnel interface.

The reliability of the proposed analytical solution is assessed by comparing with the dynamic numerical results. The results demonstrate that the proposed analytical solution performs well and can be adopted to predict the internal forces of circular tunnel under obliquely incident $P$ waves in seismic design. Based on the proposed analytical solution, parametrical studies are conducted to investigate the effect of some critical parameters on the tunnel's response, including the incident angles, the tangential contact stiffness at the 
ground-tunnel interface, and the relative stiffness between the ground and the tunnel. Some conclusions can be drawn as follows:

(1) With the increasing of the incident angle, the critical position for thrust and moment tend to move from the haunches to the vault and arch bottom. For a given oblique angle, the critical position is getting closer to the vault and arch bottom, as the ground changing from soft to hard. Moreover, there is a most unfavorable incident angle where the tunnel suffers the largest thrust or moment, which becomes being larger with the ground changing from soft to hard.

(2) There is a limited range for the tangential contact stiffness at the ground-tunnel interface, where the tangential contact stiffness has a significantly increasing and decreasing effect on the tunnel's thrust and moment, respectively. Beyond the range, the tunnel responses almost keep constant. Moreover, as the ground varying from soft to hard, the limited range for the tangential contact stiffness gradually expands.

(3) With the increasing of the relative stiffness between the ground and the tunnel, the thrust and the moment of the tunnel increase first and then decrease. There is a most unfavorable relative stiffness where the tunnel suffers the largest thrust or moment. It should be noticed that the most unfavorable relative stiffness for the thrust is larger than that of the moment.

\section{Data Availability}

The data used to support the findings of this study are available from the corresponding author upon request.

\section{Conflicts of Interest}

The authors declare that they have no conflicts of interest or personal relationships that could have appeared to influence the work reported in this paper.

\section{Acknowledgments}

This work was supported by Beijing Natural Science Foundation Program (JQ19029) and National Natural Science Foundation of China (41672289 and U1839201). The support is gratefully acknowledged.

\section{References}

[1] C. S. Prentice and D. J. Ponti, "Coseismic deformation of the Wrights tunnel during the 1906 San Francisco earthquake: a key to understanding 1906 fault slip and 1989 surface ruptures in the southern Santa Cruz Mountains, California," Journal of Geophysical Research: Solid Earth, vol. 102, no. B1, pp. 635648, 1997.

[2] D. D'Ayala and G. Benzoni, "Historic and traditional structures during the 2010 Chile earthquake: observations, codes, and conservation strategies," Earthquake Spectra, vol. 28, pp. S425-S451, 2012.

[3] P. Paultre, É Calais, J. Proulx, C. Prépetit, and S. Ambroise, "Damage to engineered structures during the 12 January 2010, Haiti (Léogâne) earthquake," Canadian Journal of Civil Engineering, vol. 40, no. 8, pp. 777-790, 2013.

[4] Ö Aydan, "Crustal stress changes and characteristics of damage to geo-engineering structures induced by the Great East Japan Earthquake of 2011," Bulletin of Engineering Geology and the Environment, vol. 74, no. 3, pp. 1057-1070, 2015.

[5] J. N. Wang, Seismic Design of Tunnels, Parsons Brinckerhoff Quade \& Douglas,Inc, New York, NY, USA, 1993.

[6] J. Penzien and C. L. Wu, "Stresses in linings of bored tunnels," Earthquake Engineering \& Structural Dynamics, vol. 27, no. 3, pp. 283-300, 1998.

[7] J. Penzien, "Seismically induced racking of tunnel linings," Earthquake Engineering \& Structural Dynamics, vol. 29, no. 5, pp. 683-691, 2000.

[8] K.-H. Park, K. Tantayopin, B. Tontavanich, and A. Owatsiriwong, "Analytical solution for seismic-induced ovaling of circular tunnel lining under no-slip interface conditions: a revisit," Tunnelling and Underground Space Technology, vol. 24, no. 2, pp. 231-235, 2009.

[9] X. Q. Fang, T. F. Zhang, B. L. Li, and R. J. Yuan, "Elastic-slip interface effect on dynamic stress around twin tunnels in soil medium subjected to blast waves," Computers and Geotechnics, vol. 119, Article ID 103301, 2020.

[10] B. L. Li, X. Q. Fang, T. F. Zhang, and S. P. Yang, "Elastic-slip interface effect on dynamic response of underwater convey tunnel in saturated poroelastic soil subjected to plane waves," Tunnelling and Underground Space Technology, vol. 103, Article ID 103468, 2020.

[11] A. Bobet, "Effect of pore water pressure on tunnel support during static and seismic loading," Tunnelling and Underground Space Technology, vol. 18, no. 4, pp. 377-393, 2003.

[12] A. Bobet, "Drained and undrained response of deep tunnels subjected to far-field shear loading," Tunnelling and Underground Space Technology, vol. 25, no. 1, pp. 21-31, 2010.

[13] J. A. S. C. Jayasinghe, M. Hori, M. R. Riaz, M. L. L. Wijerathne, and T. Ichimura, "Conversion between solid and beam element solution of finite element method based on metamodeling theory: development and application to a ramp tunnel structure," Earthquake Engineering and Engineering Vibration, vol. 16, no. 2, pp. 297-309, 2017.

[14] Y. F. Lin, A Shield Tunnel Model Based on Generalized-Node Solid-Shell and Spacial Joint Element, Springer Verlag Singapore Pte Ltd, Singapore, pp. 460-467, 2018.

[15] J.-q Huang, X.-l Du, M. Zhao, and X. Zhao, "Impact of incident angles of earthquake shear (S) waves on 3-D non-linear seismic responses of long lined tunnels," Engineering Geology, vol. 222, pp. 168-185, 2017.

[16] L. Yan, A. Haider, P. Li, and E. Song, "A numerical study on the transverse seismic response of lined circular tunnels under obliquely incident asynchronous $\mathrm{P}$ and SV waves," Tunnelling and Underground Space Technology, vol. 97, Article ID 103235, 2020.

[17] H. Yu, Y. Sun, P. Li, and M. Zhao, "Analytical solution for dynamic response of underground rectangular fluid tank subjected to arbitrary dynamic loads," Journal of Engineering Mechanics, vol. 146, no. 8, Article ID 04020077, 2020.

[18] J. Zhang, Y. Yuan, E. Bilotta, and H. Yu, "Analytical solution for seismic responses of shaft-tunnel junction under longitudinal excitations," Soil Dynamics and Earthquake Engineering, vol. 131, Article ID 106033, 2020. 
[19] J. Huang, W. Shao, M. Zhao et al., "Simplified analytical solution for circular tunnel under obliquely incident SV wave," Soil Dynamics and Earthquake Engineering, vol. 140, Article ID 106429, 2021.

[20] J. M. Zarzalejos, J. J. Aznárez, L. A. Padrón, and O. Maeso, "Influences of type of wave and angle of incidence on seismic bending moments in pile foundations," Earthquake Engineering \& Structural Dynamics, vol. 43, no. 1, pp. 41-59, 2014.

[21] J.-Q. Huang, X.-L. Du, L. Jin, and M. Zhao, "Impact of incident angles of $\mathrm{P}$ waves on the dynamic responses of long lined tunnels," Earthquake Engineering \& Structural Dynamics, vol. 45, no. 15, pp. 2435-2454, 2016.

[22] J. Huang, M. Zhao, C. Xu, X. Du, L. Jin, and X. Zhao, "Seismic stability of jointed rock slopes under obliquely incident earthquake waves," Earthquake Engineering and Engineering Vibration, vol. 17, no. 3, pp. 527-539, 2018.

[23] X. Bao, J. Liu, S. Li, F. Wang, and P. Wang, "Seismic response analysis of the reef-seawater system under obliquely incident P and SV waves," Ocean Engineering, vol. 200, Article ID 107021, 2020.

[24] B. Sun, S. Zhang, W. Cui, M. Deng, and C. Wang, "Nonlinear dynamic response and damage analysis of hydraulic arched tunnels subjected to P waves with arbitrary incoming angles," Computers and Geotechnics, vol. 118, Article ID 103358, 2020.

[25] Y. M. A. Hashash, J. J. Hook, B. Schmidt, and J. I-Chiang Yao, "Seismic design and analysis of underground structures," Tunnelling and Underground Space Technology, vol. 16, no. 4, pp. 247-293, 2001.

[26] A. C. Eringen and E. S. Suhubi, Elastodynamics, Academic Press, London, UK, 1975.

[27] X. Du, Theories and Methods of Wave Motion for Engineering, Science Press, Beijing, China, 2009, in Chinese.

[28] H. El Naggar, S. D. Hinchberger, and M. H. El Naggar, "Simplified analysis of seismic in-plane stresses in composite and jointed tunnel linings," Soil Dynamics and Earthquake Engineering, vol. 28, no. 12, pp. 1063-1077, 2008.

[29] K. Höeg, "Stresses against underground structural cylinders," Journal of the Soil Mechanics and Foundations Division, vol. 94, no. 4, pp. 833-858, 1968.

[30] J. N. Timoshenko Sp Goodier, Theory of Elasticity, McGrawHill, New York, NY, USA, 3rd edition, 1970.

[31] Y. M. A. Hashash, D. Park, and J. I.-C. Yao, "Ovaling deformations of circular tunnels under seismic loading, an update on seismic design and analysis of underground structures," Tunnelling and Underground Space Technology, vol. 20, no. 5, pp. 435-441, 2005.

[32] H. Sedarat, A. Kozak, Y. M. A. Hashash, A. Shamsabadi, and A. Krimotat, "Contact interface in seismic analysis of circular tunnels," Tunnelling and Underground Space Technology, vol. 24, no. 4, pp. 482-490, 2009.

[33] S. Kontoe, V. Avgerinos, and D. M. Potts, "Numerical validation of analytical solution and their use for equivalentlinear seismic analysis of circular tunnels," Soil Dynamics and Earthquake Engineering, vol. 66, pp. 206-219, 2014.

[34] B. Jia, "Study on the simplified analysis methods of seismic effects of underground structures," Recent Developments in World Seismology, vol. 5, pp. 42-43, 2017, in Chinese.

[35] Abaqus, Finite Element ProgramHibbit, Karlson \& Sorensen, Inc, Pawtucket, RI, USA, 2009.

[36] X. L. Du, M. Zhao, and J. T. Wang, "A stress artificial boundary in FEA for near-field wave Problem," Chinese Journal of Theoretical and Applied Mechanics, vol. 38, no. 1, pp. 49-56, 2006.
[37] M. Zhao, H. Yin, X. Du, J. Liu, and L. Liang, "1D finite element artificial boundary method for layered half-space site response from obliquely incident earthquake," Earthquakes and Structures, vol. 9, no. 1, pp. 173-194, 2015.

[38] Gb50909-2014, Code for Seismic Design of Urban Rail Transit Structures, China Planning Press, Beijing, China, 2014, in Chinese.

[39] R. B. Peck, A. J. Hendron, and B. Mohraz, "State of the art of soft-ground tunneling," Proceedings - Rapid Excavation and Tunneling Conference, vol. 1, pp. 259-285, 1972. 